\title{
Persistently low Asian paleolatitudes: Implications for the India-Asia collision history
}

\author{
Guillaume Dupont-Nivet, ${ }^{1,2}$ Douwe J. J. van Hinsbergen, ${ }^{3,4}$ and Trond H. Torsvik ${ }^{3,5,6}$
}

Received 9 December 2008; revised 4 June 2010; accepted 15 June 2010; published 14 October 2010.

[1] Paleomagnetism provides independent paleolatitude constraints on the India-Asia convergence. However, implied Cenozoic latitudinal convergence within Asia (thousands of $\mathrm{km}$ ) largely exceeds geologic estimates of tectonic shortening (hundreds of $\mathrm{km}$ ). This discrepancy may result from a notoriously low bias in paleomagnetically determined Cenozoic paleolatitudes in Asia. We provide here new paleomagnetic data from Cenozoic Mongolian volcanic rocks and from Chinese Paleogene sediments corrected from the depositional bias of inclination shallowing. These results combined with similar Asian data sets, confirm that paleolatitudes are still $5-10^{\circ}$ lower than predicted by the paleomagnetic Apparent Polar Wander Path (APWP) for Asia between 50 and $20 \mathrm{Ma}$. Inclination-shallowing being excluded from the selected data sets, we investigate the likeliness of other proposed mechanisms for this discrepancy: (1) more southerly positions of Asia than expected by the APWP (due to APWP inaccuracies rather than Eurasian non-rigidity), or (2) non-dipolar geomagnetic field contributions. Fully explaining this discrepancy by only one of these mechanisms would imply either unrealistically large $\left(>10^{\circ}\right)$ APWP inaccuracies, or unrealistically large octupolar field contributions (up to 16\%). A combination of these mechanisms is found more likely to have produced the observed latitudinal discrepancy, but their respective contributions cannot be quantified given the still relatively low amount and poor quality of Cenozoic paleomagnetic data from stable cratons of Asia, India, and Europe. By allowing for reasonable time-dependant non-dipolar contributions and a slight $\left(<5^{\circ}\right)$ APWP bias, the latitudinal discrepancy can be resolved and the excessive amounts of intra-Asian shortening decrease to values in line with tectonic shortening from structural

\footnotetext{
${ }^{1}$ Paleomagnetic Laboratory "Fort Hoofddijk," Faculty of Geosciences, Utrecht University, Utrecht, Netherlands.

${ }^{2}$ Key Laboratory of Orogenic Belts and Crustal Evolution, Ministry of Education, Peking University, Beijing, China.

${ }^{3}$ Physics of Geological Processes, University of Oslo, Oslo, Norway.

${ }^{4}$ Department of Geology, Leicester University, Leicester, UK.

${ }^{5}$ Also at Center for Geodynamics, NGU, Trondheim, Norway.

${ }^{6}$ Also at School of Geosciences, University of the Witwatersrand, Johannesburg, South Africa.

Copyright 2010 by the American Geophysical Union. 0278-7407/10/2008TC002437
}

studies. Citation: Dupont-Nivet, G., D. J. J. van Hinsbergen, and T. H. Torsvik (2010), Persistently low Asian paleolatitudes: Implications for the India-Asia collision history, Tectonics, 29, TC5016, doi:10.1029/2008TC002437.

\section{Introduction}

[2] The Cenozoic India-Asia convergence resulted in the formation of the Tibetan Plateau (Figure 1), the highest elevated landmass on the planet, with major repercussions on regional environments and possibly on global climate [Ruddiman et al., 1997; Tapponnier et al., 2001]. Despite its importance and decades of research, the convergence history and the timing and of the collision between these continents remains controversial [Aitchison et al., 2008; Copley et al., 2010; Garzanti, 2008; Molnar and Stock, 2009]. The continental convergence history is based mainly on two data sets. India-Asia relative convergence rates and amounts are estimated through time using plate kinematic reconstructions built on the basis of Euler poles determined from marine magnetic anomalies defining a plate circuit [Cox and Hart, 1986]. The position through time of the plate circuit with respect to Earth's magnetic field is constrained by paleomagnetic data from all continents rotated into a synthetic global Apparent Polar Wander Path (APWP) using the plate circuit [Besse and Courtillot, 2002; Cox and Hart, 1986; Schettino and Scotese, 2005; Torsvik et al., 2008]. The paleolatitudes of terranes that are not incorporated in the plate circuit - such as the Tethyan Himalayas, the Lhasa or the Qiangtang terranes between India and Siberia - can be determined independently with paleomagnetic data directly from these terranes. These can be compared to paleolatitudes of the bounding plates (i.e., India or Eurasia) constrained by the global APWP in order to quantify their respective latitudinal motion. Despite its importance for kinematic reconstructions, the paleomagnetic database on which the APWP is based is sparse and its interpretation is not straightforward. In particular, Cenozoic Asian inclinations appear to be significantly $\left(>10^{\circ}\right)$ lower than predicted by the APWP [Cogné et al., 1999; Hankard et al., 2007a]. This directly hampers paleolatitude estimates of India and Asia, and their use in determining convergence rates and convergence magnitudes of terranes with respect to India or Siberia.

[3] The cause for the shallow 'bias' in Asian paleomagnetic inclinations is the topic of a longstanding debate. Proposed causes include: (1) more southerly position of Asia due to tectonic decoupling of Asia from Eurasia during the Cenozoic [Ali and Aitchison, 2006; Cogné et al., 1999]; (2) non-dipolar (mostly octopular) contributions to the otherwise dipolar geomagnetic field [Chauvin et al., 1996; Si and Van der Voo, 


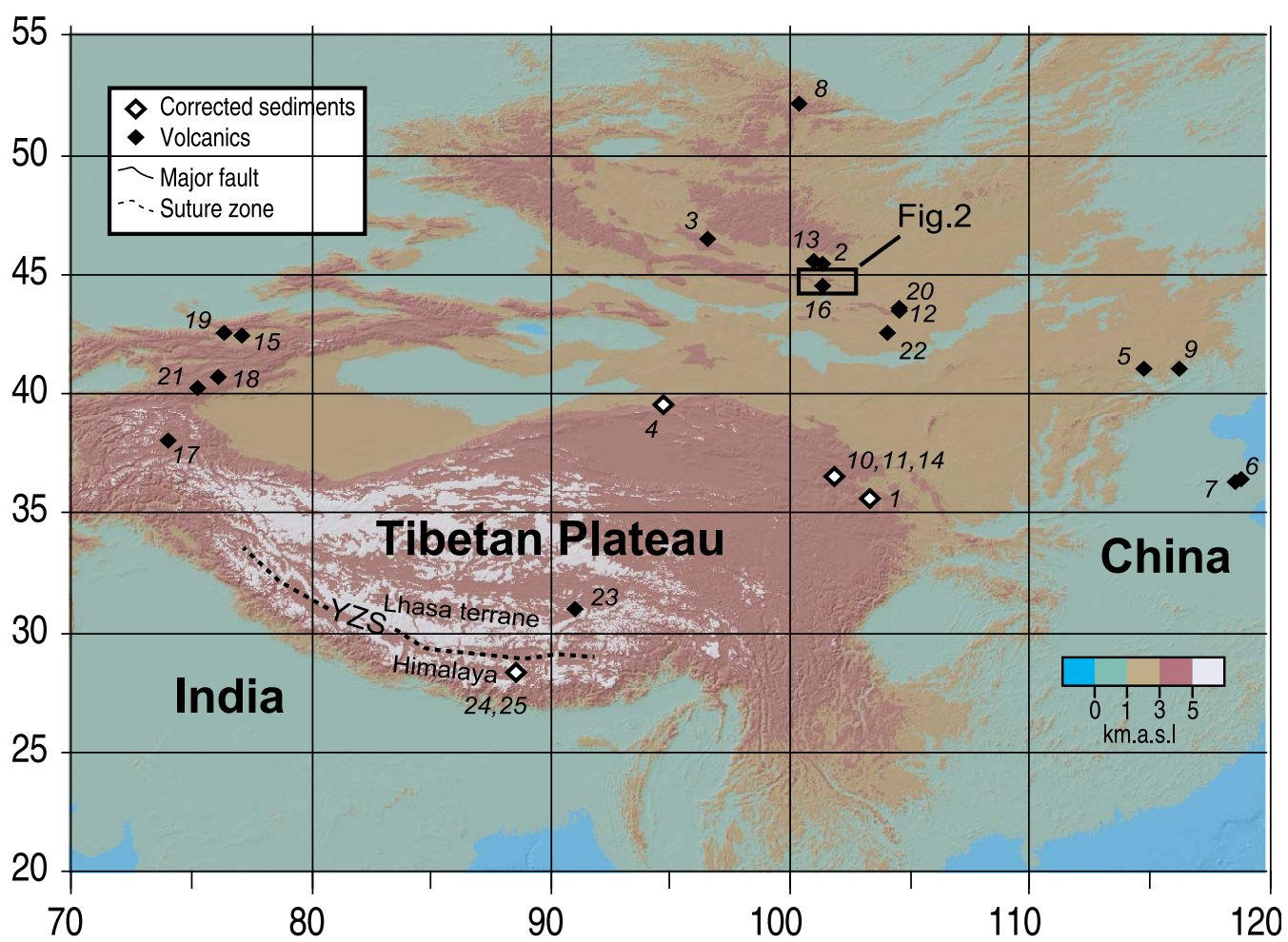

Figure 1. Digital elevation model (scale is in kilometers above sea level: km a.s.l.) with location of sampling (box labeled Figure 2) and numbered paleomagnetic data sets included in the compilation (only from volcanic rocks and shallowing-corrected sediments).

2001]; (3) 'inclination shallowing' during deposition and compaction of sediments [Dupont-Nivet et al., 2002; Gilder et al., 2001; Tan et al., 2003; Tauxe, 2005], or a combination of these causes.

[4] To better constrain the Asian inclination anomaly, as basis for a discussion on its possible mechanisms and its implications on the India-Asia collision, we provide in this paper: (1) new paleomagnetic data from 40, 30 and $10 \mathrm{Ma}$ volcanic rocks from Mongolia and (2) a careful review of reliable Asian paleomagnetic data sets (exclusively from volcanic rocks or from shallowing-corrected sedimentary rocks).

\section{New Paleomagnetic Data From Cenozoic Volcanics of Mongolia}

[5] Paleomagnetic poles are best determined from paleomagnetic data obtained from well-bedded volcanic sequences in stable continental regions. The Gobi Altai region in Mongolia (Figure 1) has belonged to stable Eurasia since the late Jurassic [Cogné et al., 1999; Hankard et al., 2007a; Van der Voo et al., 1999; van Hinsbergen et al., 2008]. Between $\sim 190 \mathrm{Ma}$ and the late Miocene, the region has undergone little or no internal deformation or erosion prior to the late Miocene strike-slip dominated deformation [Jolivet et al., 2007; Vassallo et al., 2007]. Similarity between Cretaceous Mongolian poles and the APWP led van Hinsbergen et al. [2008] to suggest that late Cenozoic deformation did not involve vertical axis rotations. As such, paleomagnetic poles obtained from post-Jurassic lavas from the Gobi Altai can be considered to reflect the paleoposition of stable Eurasia. Recently, Hankard et al. [2007a] provided paleomagnetic results from Cenozoic volcanic and shallow intrusive bodies in the Gobi Altai and the Valley of Lakes (Figure 2). Here, we report new paleomagnetic data from the same region (and in one case from the same locality) to determine Asian poles at $\sim 40, \sim 30$ and $\sim 10 \mathrm{Ma}$.

\subsection{Geological Setting and Sampling}

[6] The Gobi Altai exposes Paleozoic basement overlain by some Jurassic, and mainly lower Cretaceous basalts and terrestrial sediments [Jolivet et al., 2007; van Hinsbergen et al., 2008], as well as scattered Cenozoic basaltic lavas and shallow intrusive basaltic plugs with ages ranging from $\sim 40$ to $\sim 10 \mathrm{Ma}$ [Barry et al., 2003; Devyatkin and Smelov, 1980; Hankard et al., 2007b; Höck et al., 1997; Whitford-Stark, 1987]. The latter were the target of our paleomagnetic sam-

Figure 2. Earth satellite image of the Gobi Altai with the main structural elements and sampling locations. TB $=$ Tsagaanbotga rhyolite plug. The Sevrei plateau is located southeast of this region. Field photographs show the sampling locations and an impression of the topography and structure of the region. 


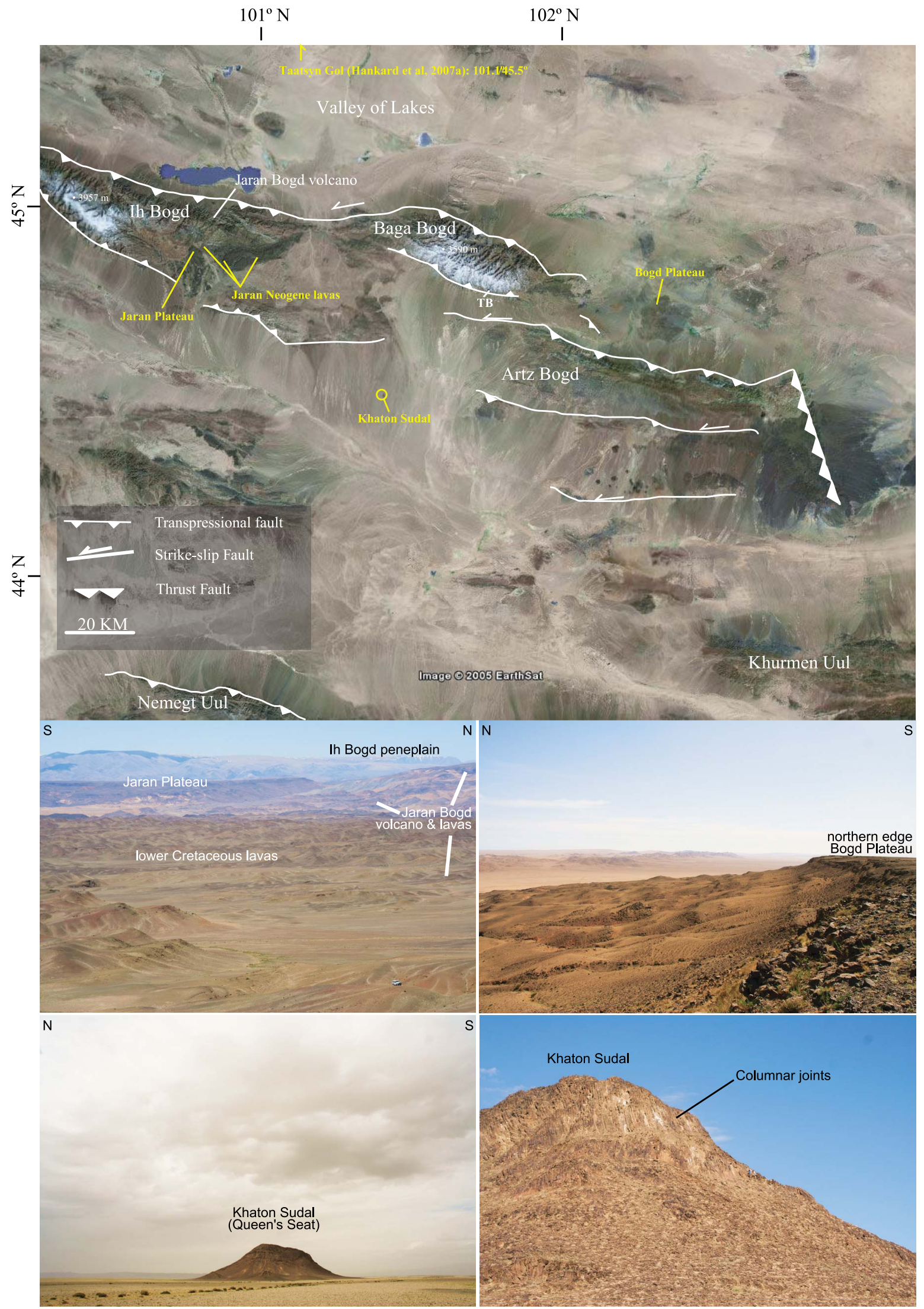

Figure 2 


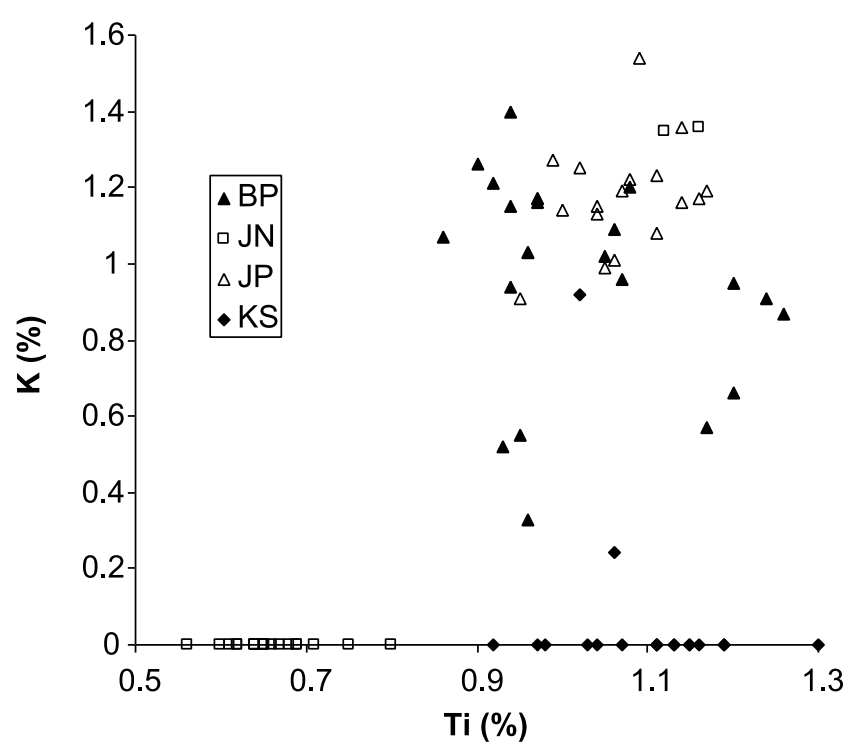

Figure 3. Major element concentration ( $\mathrm{K}$ and $\mathrm{Ti}$ given in equivalent $\%$ weight) showing the signatures of lavas from the Bogd Plateau (BP), Jaran Plateau (JP), Jaran Neogene (JN) and Khaton Sudal (KS).

pling. The Gobi Altai mountain range probably forms a farfield effect of the India-Asia collision and is dominated by transpressional strike-slip motion along elongated $\sim$ ENEWSW trending restraining bends [Bayasgalan et al., 1999; Cunningham, 2005, 2007; Cunningham et al., 1996, 1997]. It is important to note here that the $\sim$ ENE-WSW trend of these restraining bends implies that associated tilting may be to the north or south, thus potentially influencing inclination/ paleolatitude estimates. It is therefore important to accurately determine post-depositional tilting.

[7] Paleomagnetic sampling of 288 samples from 37 lava sites was performed using a water-cooled, gasoline-powered, motor drill. To exclude any local magnetic deviations, the orientation of all samples was measured with both a magnetic and a sun compass, and magnetic measurements were corrected for the present-day declination. Sampling was performed at three localities of $\sim 40,30$ and $10 \mathrm{Ma}$, respectively:

[8] 1. The oldest sampled locality $(39.4 \pm 0.6 \mathrm{Ma}$ [Hankard et al., 2007b]) consists of a small array of columnar jointed basaltic plugs, the largest one of which is called Khaton Sudal ('Queen's Seat'), rising $50 \mathrm{~m}$ above the surrounding plains (Figure 2). We collected 49 samples from 7 sites from these plugs. Similar to Hankard et al. [2007b], we assume these plugs not been affected by significant tilt, as suggested by the negligible $\left(<2^{\circ}\right)$ slope of the surrounding alluvial plains which probably represent the underlying, pre-intrusive bedding.

[9] 2. A volcanic episode occurring around $30 \mathrm{Ma}$ is preserved in several basaltic plateaus of a few $\mathrm{km}^{2}$. On the Bogd plateau we collected 98 samples at 14 sites, and on the Jaran plateau we collected 70 samples from 10 sites (Figure 2). Barry et al. [2003] obtained ${ }^{40} \mathrm{Ar} /{ }^{39} \mathrm{Ar}$ ages from the Bogd plateau lavas of $33.0 \pm 0.3$ and $32.4 \pm 0.4 \mathrm{Ma}$, and from similar lavas from the Sevrei plateau further south at $30.3 \pm$ $0.1 \mathrm{Ma}$. The Jaran Plateau is a lava plateau of similar size, lithology (dark, glassy pahoehoe lavas) and regional setting. Because it has never been directly dated, we confirmed this correlation through geochemistry analysis using a NITON XRF analyzer. Major element mapping shows that sampled lavas from the Bogd and Jaran plateaus have a common signature that is noticeably distinct from the widespread Cretaceous, Khaton Sudal or Neogene lavas (Figure 3). Bedding of the Jaran and Bogd plateaus is $2-3^{\circ}$ in E-SE direction (Table 1). Although potentially primary, we chose to correct for this very minor bedding tilt. Given the strong E-component of the tilt, correction does not lead to significant changes of the inclination.

[10] 3. A set of 70 samples was collected at 10 sites in young lavas that fill a paleovalley next to the Jaran Plateau, here depicted as 'Jaran Bogd Neogene lavas' (Figure 2). These lavas originated from the only volcano that is still evident in the Gobi Altai region (the Jaran Bogd volcano), and form isolated flows from the crater to the east and south, over a distance of up to $\sim 20 \mathrm{~km}$. Given the absence of radiometric ages on these lavas, we estimate their time of deposition to be late Miocene-Pliocene based on crosscutting relationships. They fill a paleovalley that formed next to the Jaran Plateau. The valley must post-date the eruption of the Jaran Plateau (JP) lavas. The paleovalley formed at the northern edge of Mt. Ih Bogd on which Jolivet et al. [2007] and Vassallo et al. [2007] dated an uplifted peneplain and showed that this erosion surface most likely formed in the Jurassic, and was not demonstrably incised until the uplift of the Ih Bogd restraining bend, the onset of which they dated at $5 \pm 3$ Ma by apatite fission track analysis. The present-day valley is located west of the youngest lavas, and incised several tens of meters deeper. Given these crosscutting relationships, the paleomagnetic results from these upper Miocene to Pliocene lavas are expected to range between the present-day field and the $\sim 10$ Ma paleopole obtained in the Valley of Lakes [Hankard et al., 2007a]. Both the plateau and the upper Miocene-Pliocene lavas unconformably cover a folded, 1000-1500 m thick sequence of lower Cretaceous basalts [van Hinsbergen et al., 2008]. Given the very minor tilt of the Jaran Plateau, we have not applied a tilt correction for the Neogene lavas.

[11] Finally, 28 samples were collected at 4 sites from a rhyolite plug on the southern flank of Baga Bogd (Tsagaanbotga), but these did not yield interpretable paleomagnetic directions (Table 1).

\subsection{Paleomagnetic Procedures}

[12] The samples were demagnetized using either thermal (TH) or alternating field (AF) progressive demagnetization. Heating took place in a magnetically shielded, laboratorybuilt furnace using small temperature increments of $20-80^{\circ} \mathrm{C}$ up to temperatures of $640^{\circ} \mathrm{C}$. AF demagnetization was carried out with 5-20 mT increments up to $120 \mathrm{mT}$. For all samples, the natural remanent magnetization (NRM) of the specimens was measured on a $2 \mathrm{G}$ Enterprises horizontal DC SQUID cryogenic magnetometer (noise level $3 \times 10^{-12} \mathrm{Am}^{2}$ ). For AF demagnetization, the instrument was interfaced with an in-house developed robot-assisted automated measuring device. 


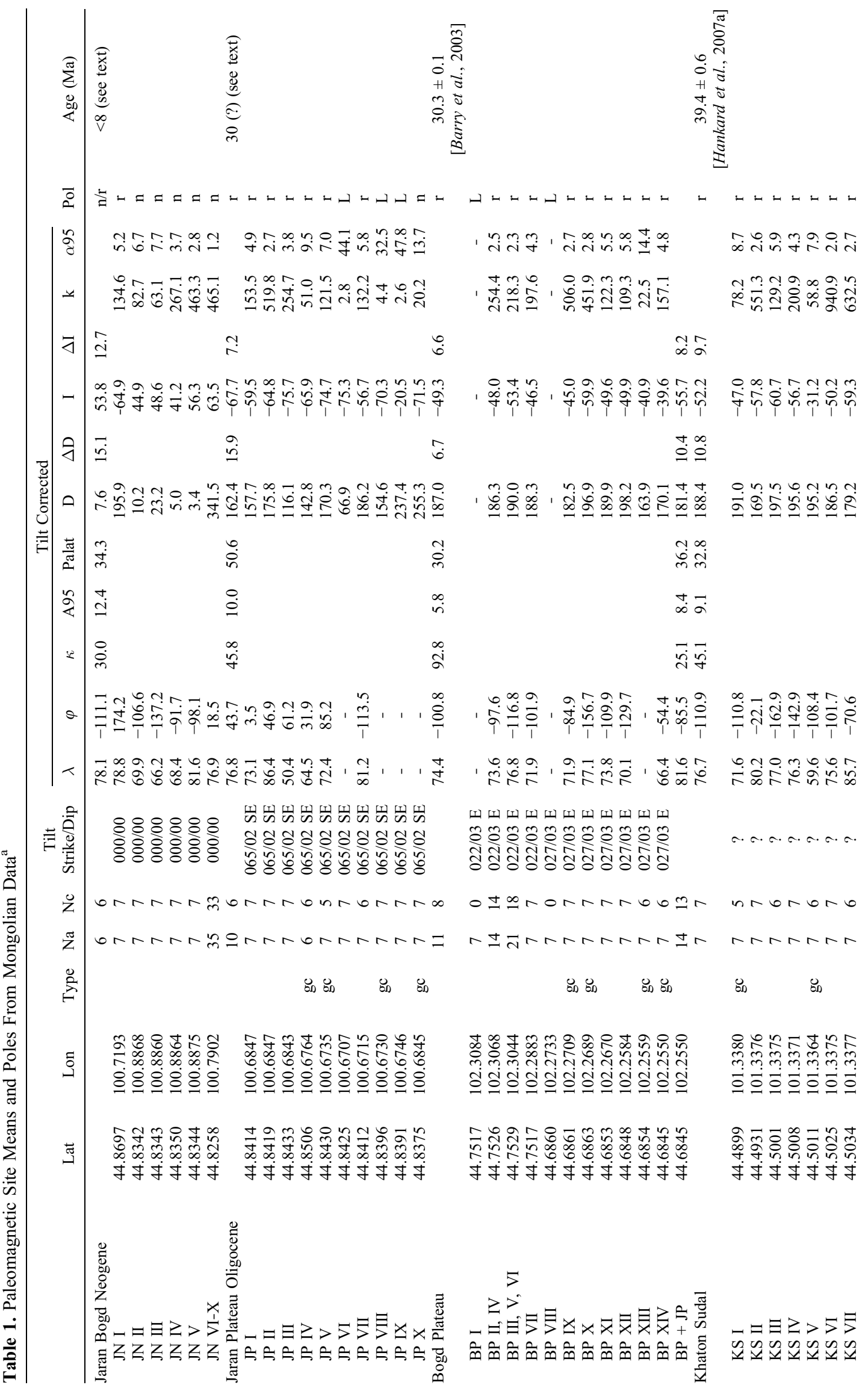




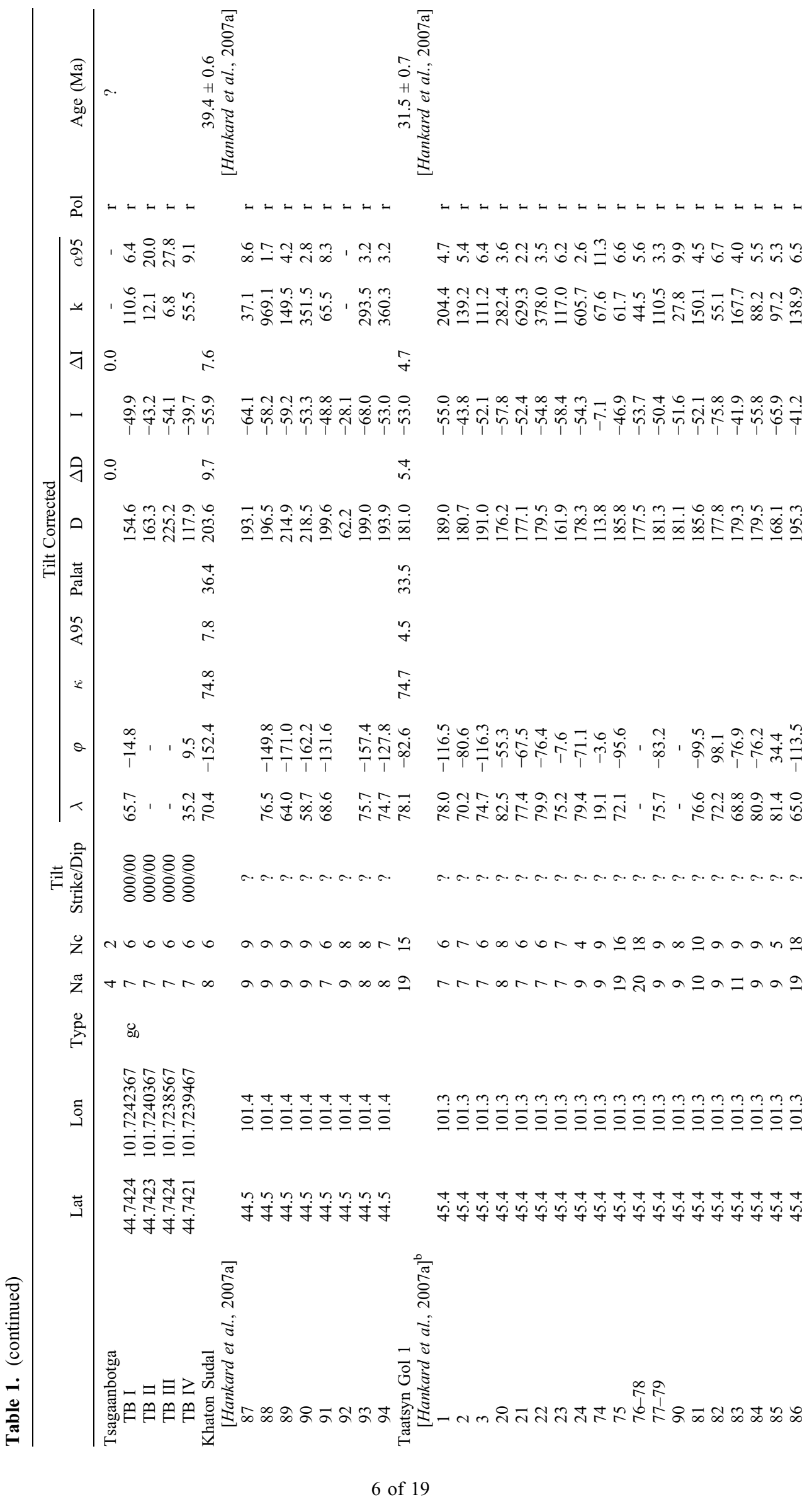




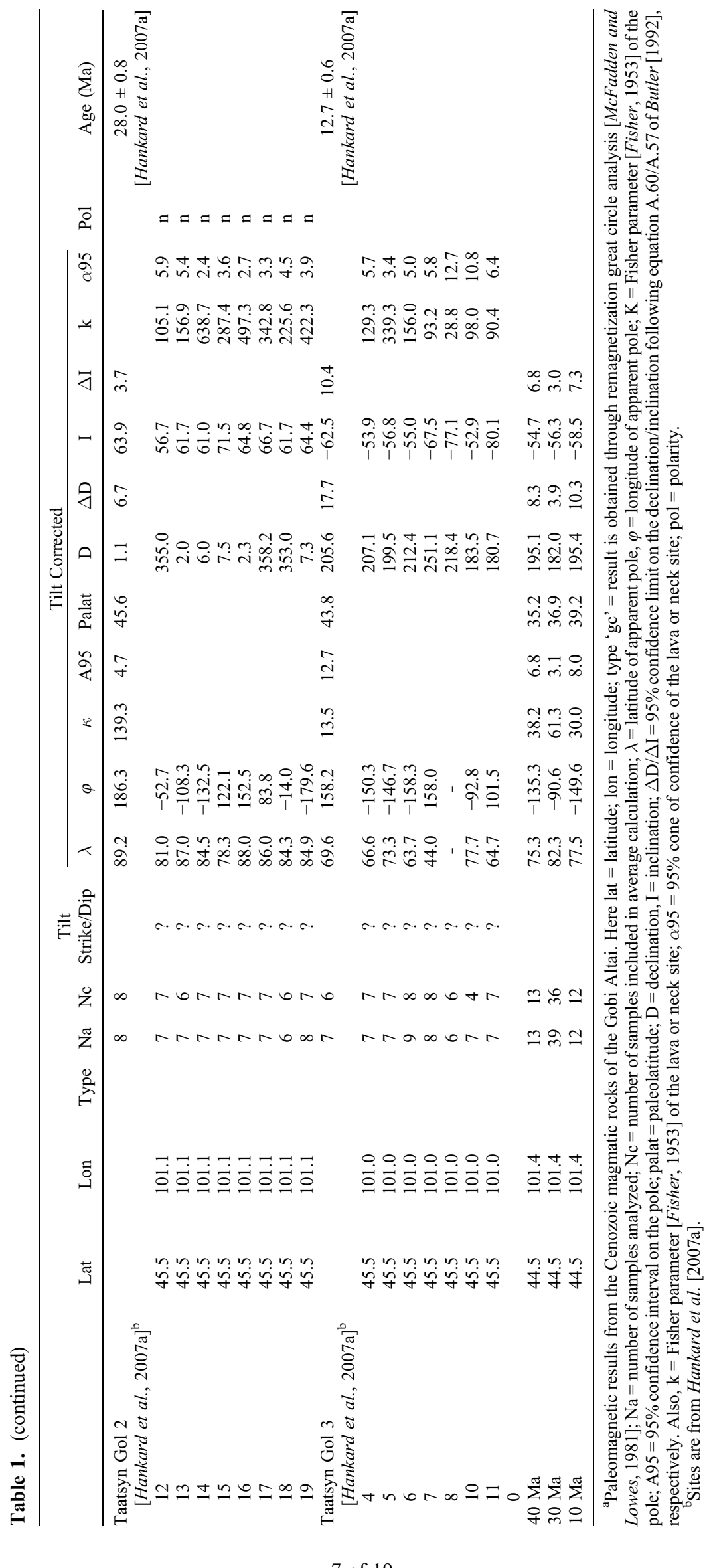


[13] The demagnetization diagrams of the NRM were plotted in orthogonal vector diagrams [Zijderveld, 1967]. In addition, a number of multicomponent samples were plotted on equal-area projections (Figure 4).

[14] Initially, we thermally demagnetized one sample for each site. Depending on the resulting demagnetization behaviors, the remaining samples of the sites were processed either by AF or TH demagnetization. Initial intensities typically range from 0.5 to $2.0 \mathrm{~A} / \mathrm{m}$. The $\mathrm{AF}$ demagnetized samples show good agreement with the TH samples of the same site. At a number of sites, the ChRM was not recognized in the TH demagnetization but could clearly be determined by AF demagnetization. To further assess rock magnetic properties and possible magnetic mineralogy, low temperature thermomagnetic runs were performed on representative basalts from each locality (Figure 5). All processed samples have well-defined Curie temperatures at around $570^{\circ} \mathrm{C}$ suggesting the presence of Ti-poor titanomagnetite or pure magnetite [Dunlop and Özdemir, 1997]. The similarity between heating and cooling curves (in particular in the 0-400-0 runs) suggests little thermochemical alteration of this phase during processing. In general, the slightly lower susceptibility values in the cooling curve after $700^{\circ} \mathrm{C}$ suggests partial destruction of this phase at high temperature. These rock magnetic experiments confirms the suggestion that the thermal and AF ChRM is carried by a stable phase such as Ti-poor titanomagnetite or magnetite, provided by demagnetization results showing straightforward ChRM directions demagnetized between 500 and $600^{\circ} \mathrm{C}$ and 5$40 \mathrm{mT}$ respectively.

\subsection{ChRM Directions}

[15] Identification of the characteristic remanent magnetization (ChRM) was done by principal component analysis [Kirschvink, 1980]. When vector end-points showed a trend toward the origin of the diagram, we determined this component to be the ChRM. Samples were rejected from further analysis if the maximum angular deviation (MAD) exceeded $15^{\circ}$. Because lava site mean directions should represent spot-readings of the Earth's magnetic field paleosecular variation (PSV), within-site errors can be assumed to be random, and averages and confidence ovals on lava site level were determined by Fisher [1953] statistics (Table 1). We excluded lava sites with $\mathrm{k}<50$ from further analysis, since variations between samples within a single lava flow should be minimal. In the remaining lava sites, lightning-induced remagnetization was recognized in five sites. The identification of lightning-induced NRM is based on abnormally high magnetic intensity, together with within-site randomness of NRM directions. In some cases, an overprint caused by lightning or gyroremanent remagnetization [Dankers and Zijderveld, 1981] could be identified and eliminated using the great circle approach of McFadden and McElhinny [1988]. The sites from Khaton Sudal yielded significantly different directions (not sharing a common true mean direction) and therefore likely represent individual spot readings of PSV resulting from diachronous cooling below the Curie-temperature of the basaltic intrusion. For the Jaran Plateau and the Bogd Plateau, as well as for the Jaran Neogene lavas, it was not always possible in the field to discriminate between individual lavas. Moreover, eruption of multiple lavas may have occurred within a very short time period, providing the same paleomagnetic spot reading of PSV when analyzed. We have combined sites which shared a common true mean direction [McFadden and Lowes, 1981], as we suspect these to represent the same spot reading of PSV (sites JN VI-X, sites BP II and IV, and sites BP III, V and VI were combined). After the above eliminations and combinations, we determine seven mean directions providing individual spot readings of the PSV for Khaton Sudal, six for the Jaran Plateau, eight for the Bogd Plateau and six for the Jaran Neogene lavas (Table 1).

\subsection{Paleomagnetic Poles and Directions}

[16] Because scatter of paleomagnetic directions induced by PSV is near-Fisherian at the poles, but ellipsoid elsewhere on the globe [Tauxe and Kent, 2004], we calculated our lava site mean directions into poles and determined locality means on the poles using Fisher [1953] statistics. Outlying lava sites were excluded from the determination of locality means when their poles were rejected by the Vandamme [1994] criterion (Figure 6). The average pole was then calculated into an average declination (D) and inclination (I), with associated $95 \%$ confidence limits $\Delta \mathrm{D}$ and $\Delta \mathrm{I}$, respectively, following Butler [1992] (Table 1). Combining our data with previous results from the sampling region [Hankard et al., 2007a] leads to the following poles:

[17] 1. A $\sim 40$ ma pole is obtained from Khaton Sudal by combining our results with those of Hankard et al. [2007a]. After applying our cut-off for within-site scatter of $\mathrm{k}=50$ (excluding four sites) we derive a pole of $(75.3 /-135.3 / 38.2 /$ $6.8=\lambda / \varphi / \mathrm{K} / \mathrm{A} 95)$. It is interesting to note that re-sampling of the locality Khaton Sudal yielded significantly different result $\left(\mathrm{D} \pm \Delta \mathrm{D} / \mathrm{I} \pm \Delta \mathrm{I}=203.6^{\circ} \pm 9.7^{\circ} /-55.9^{\circ} \pm 7.6^{\circ}\right.$ of Hankard et al. [2007a] versus $188.4^{\circ} \pm 10.8^{\circ} /-52.2^{\circ} \pm 6.6^{\circ}$ (this study)). Since the methods used by Hankard et al. [2007a] are similar to ours, and there is no bedding tilt correction, this difference reflects that the use of only seven or eight individual spot readings is insufficient to reliably determine a paleomagnetic pole, as suggested by Van der Voo [1990].

[18] 2. A 30 Ma pole is obtained by combining the Jaran and Bogd Plateau results with those of Hankard et al. [2007a] from the Valley of Lakes (Figure 2). Our results show significantly different mean directions for the Jaran and Bogd Plateaus respectively $\left(\mathrm{D} \pm \Delta \mathrm{D} / \mathrm{I} \pm \Delta \mathrm{I}=162.4^{\circ} \pm 15.9^{\circ}\right.$ / $-67.7^{\circ} \pm 7.2^{\circ}$ versus $187.0^{\circ} \pm 6.7^{\circ} /-49.3^{\circ} \pm 6.6^{\circ}$ ). This cannot be explained by erroneous tilt corrections (because both plateaus have very low tilts), or by tectonic deflection of declination (since the underlying Cretaceous lavas show no

Figure 4. Typical paleomagnetic data from each Mongolian locality. From left to right: Samples - demagnetization diagrams (thermal for JN35, JP11, BP73, and alternating field for KS 47); Sites - example of ChRM directions from typical site; Localities - site-mean directions for each locality means shown on equal area projections with closed (open) symbols projected on the lower (upper) hemisphere. Data are listed in Table 1. 


\section{Samples}
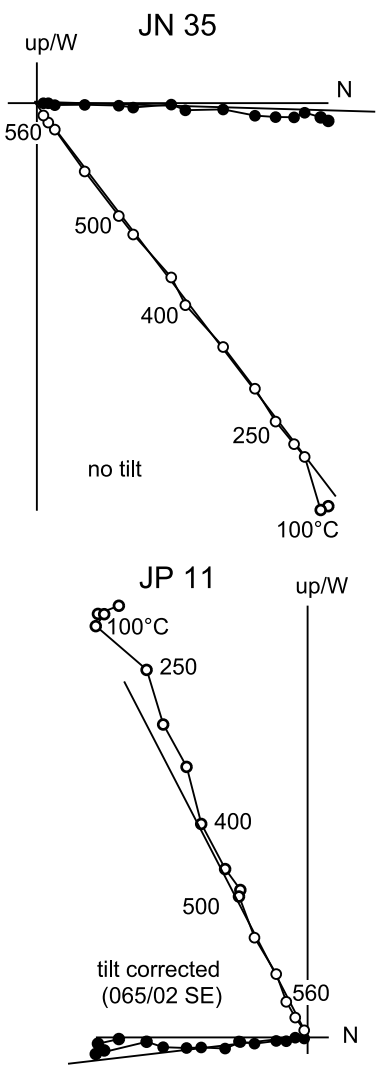

BP 73
Sites

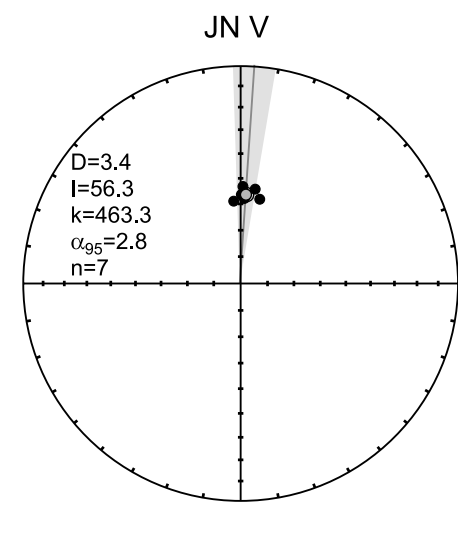

Localities

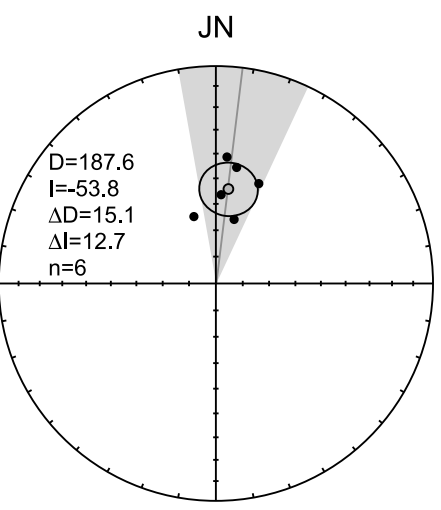

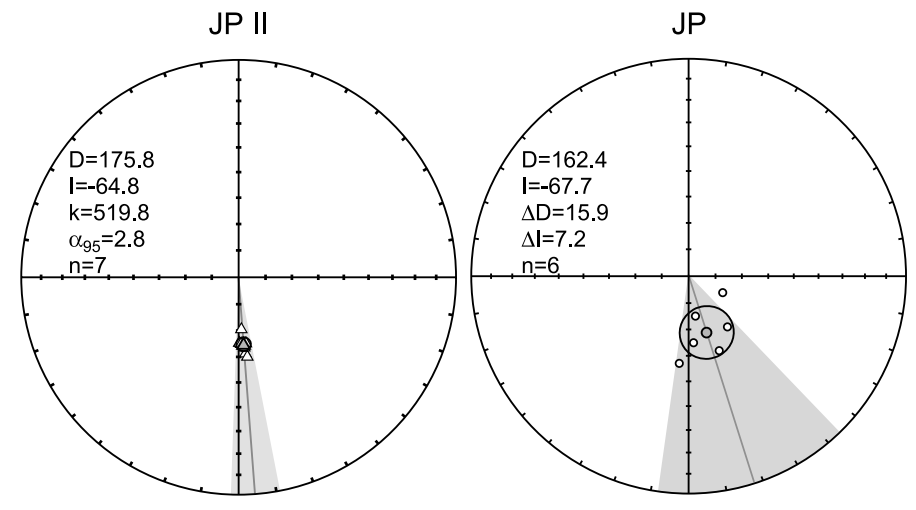
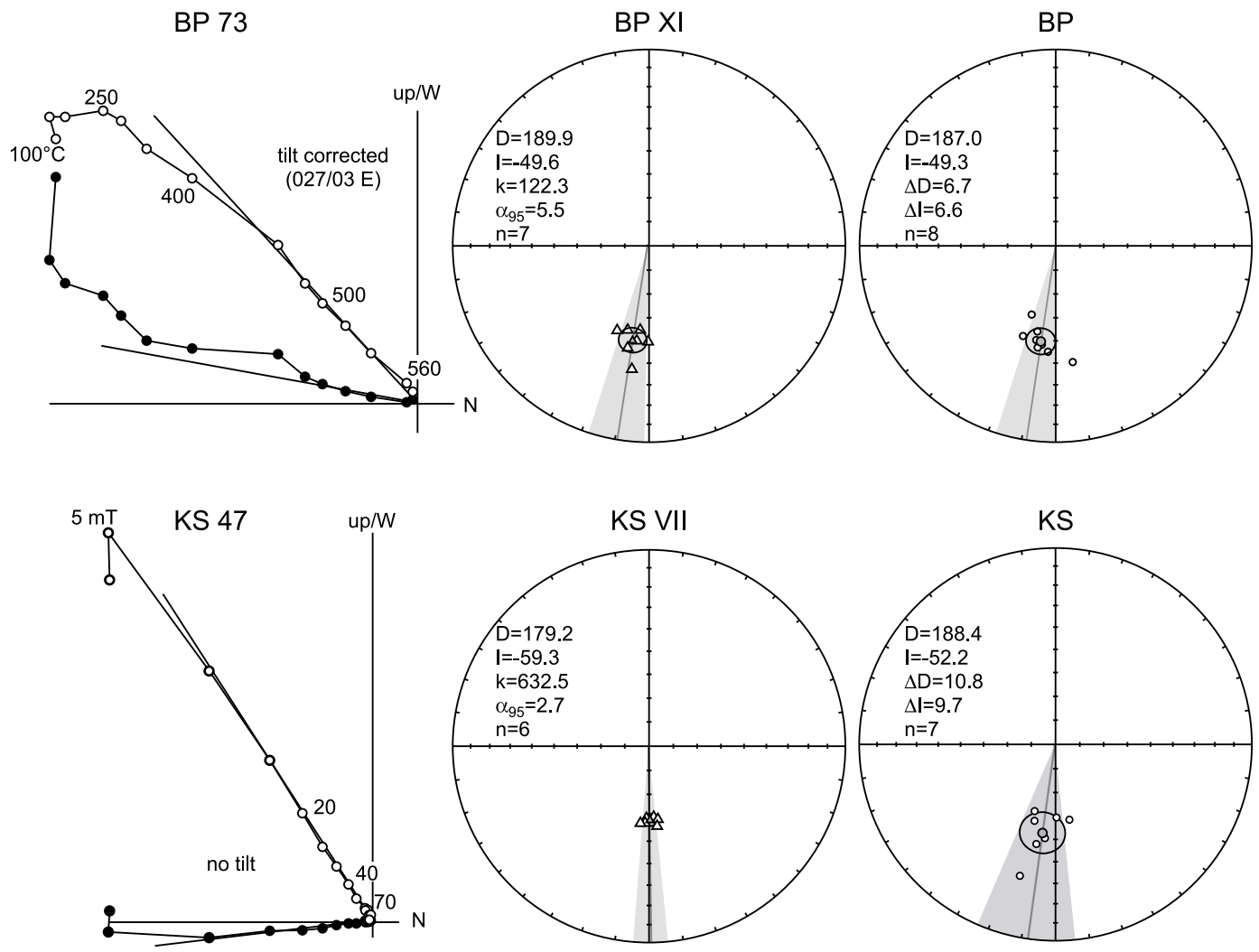

Figure 4

9 of 19 

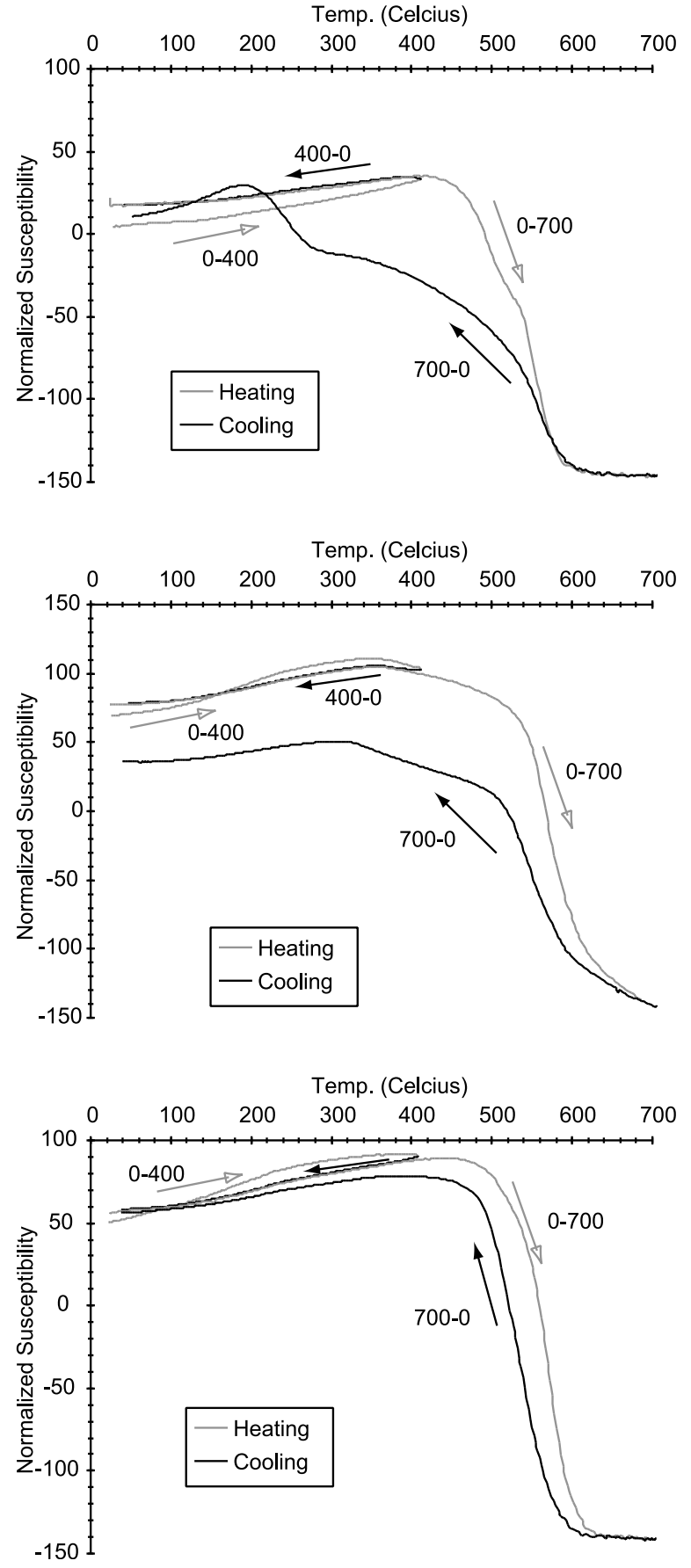

Figure 5. Susceptibility versus temperature for representative samples acquired by low field thermomagnetic runs $\left(0-400-0^{\circ} \mathrm{C}\right.$ followed by $\left.0-700-0^{\circ} \mathrm{C}\right)$ on Kappabridge KLY3-CS.

evidence for significant vertical axis rotations throughout the Gobi Altai [van Hinsbergen et al., 2008]). Therefore, we explain this difference as solely the result of PSV. A $\sim 30 \mathrm{Ma}$ paleopole $(\lambda / \varphi / \mathrm{K} / \mathrm{A} 95=82.3 /-90.6 / 61.3 / 3.1)$ is obtained by combining our sites with results from Hankard et al. [2007a], after applying the cutoff of Vandamme [1994].
[19] 3. A 10 Ma pole is obtained by combining our results from the Jaran Neogene lavas with those from the Valley of Lakes of Hankard et al. [2007a] dated at $12.7 \pm 0.6 \mathrm{Ma}$. Although there may be a time difference between these results of up to $10 \mathrm{Ma}$, minimal expected paleolatitudinal motion of Eurasia within this time span allows the combined pole to be confidently used for comparison with the $10 \mathrm{Ma}$ Eurasian APWP pole of Torsvik et al. [2008]. The combined data of Hankard et al. [2007a] and this paper yields a new pole $(\lambda / \varphi /$ $\mathrm{K} / \mathrm{A} 95=77.5 / 179.6 / 30.0 / 8.0 ; \mathrm{n}=12$ ).

[20] The three combined poles have angular deviations of $\mathrm{S}=20.2$ for the $10 \mathrm{Ma}$ pole, $\mathrm{S}=12.3$ for $30 \mathrm{Ma}$, and $\mathrm{S}=13.2$ for $40 \mathrm{Ma}$. These are close to the range of secular variation induced dispersions estimated for the last $5 \mathrm{Ma}$ [Johnson et al., 2008], and well within the limits for scatters reconstructed for the Jurassic (with frequent reversals) and Cretaceous (with few reversals) [Biggin et al., 2008]. We thus

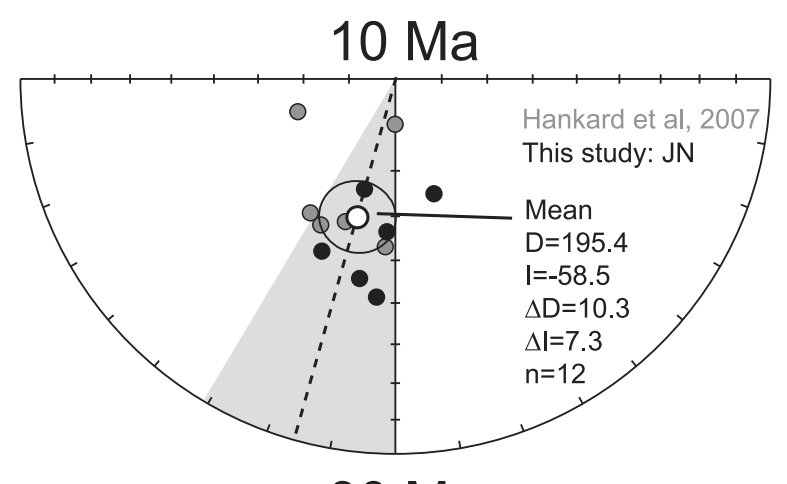

\section{$30 \mathrm{Ma}$}

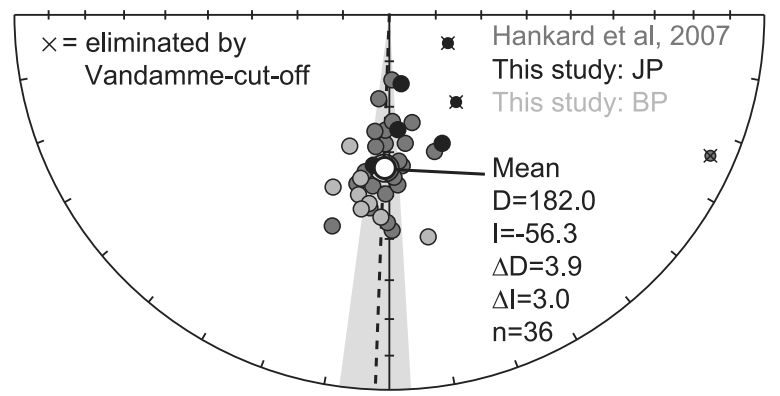

\section{$40 \mathrm{Ma}$}

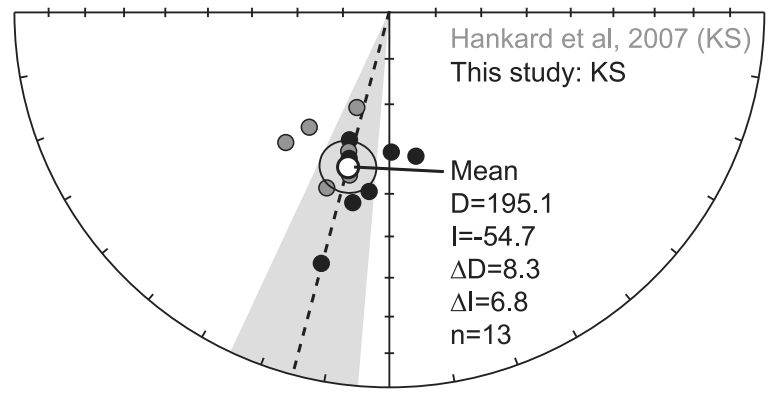

Figure 6. Average paleomagnetic directions per time slice shown on equal area projections, combining the new data in this paper with previously published site-mean directions from the same region [Hankard et al., 2007a]. 
Table 2. Shallowing-Corrected Sedimentary Data Sets ${ }^{\mathrm{a}}$

\begin{tabular}{|c|c|c|c|c|c|c|c|c|c|c|c|c|c|c|c|c|c|c|c|c|}
\hline \multirow[b]{2}{*}{ Data Set } & \multirow[b]{2}{*}{$\begin{array}{l}\text { Age } \\
\text { (Ma) }\end{array}$} & \multicolumn{2}{|c|}{ Site Location } & \multicolumn{6}{|c|}{ Observed Direction } & \multicolumn{4}{|c|}{ Reference Pole } & \multicolumn{2}{|c|}{ Expected } & \multicolumn{4}{|c|}{ Corrected } & \multirow[b]{2}{*}{ Ref } \\
\hline & & $\begin{array}{l}\text { Lat } \\
\left({ }^{\circ} \mathrm{N}\right)\end{array}$ & $\begin{array}{l}\text { Long } \\
\left({ }^{\circ} \mathrm{E}\right)\end{array}$ & $\begin{array}{c}\text { D } \\
(\operatorname{deg})\end{array}$ & $\begin{array}{c}\mathrm{I} \\
(\mathrm{deg})\end{array}$ & $\begin{array}{c}\mathrm{k} \\
(\mathrm{deg})\end{array}$ & $\begin{array}{c}\alpha_{95} \\
(\mathrm{deg})\end{array}$ & $\mathrm{n}$ & $\begin{array}{l}\text { Plat } \\
\text { (deg) }\end{array}$ & Age & $\begin{array}{l}\text { Lat } \\
\left({ }^{\circ} \mathrm{N}\right)\end{array}$ & $\begin{array}{l}\text { Long } \\
\left({ }^{\circ} \mathrm{E}\right)\end{array}$ & $\begin{array}{l}A_{95} \\
(\mathrm{deg})\end{array}$ & $\begin{array}{c}\mathrm{I} \pm \Delta \mathrm{I} \\
(\mathrm{deg})\end{array}$ & $\begin{array}{l}\text { Plat } \\
\text { (deg) }\end{array}$ & $\begin{array}{l}\mathrm{I}_{\text {cor }} \\
(\mathrm{deg})\end{array}$ & $\begin{array}{c}\mathrm{I}_{-} \\
(\mathrm{deg})\end{array}$ & $\begin{array}{c}\mathrm{I}_{+} \\
(\mathrm{deg})\end{array}$ & $\begin{array}{l}\text { Plat } \\
\text { (deg) }\end{array}$ & \\
\hline \multicolumn{21}{|c|}{ APWP Eurasia } \\
\hline \multicolumn{21}{|l|}{ Stable Asia } \\
\hline Ctg-Xsh & $23-17$ & 36.531 & 101.862 & 7 & 45 & 12 & 4 & 95 & 26 & 20 & 85 & 137 & 3 & $60 \pm 3$ & 40.5 & 52 & 45 & 63 & 33 & 1 \\
\hline Xiejia & $30-23$ & 36.528 & 101.863 & 5 & 50 & 12 & 3 & 185 & 31 & 20 & 85 & 137 & 3 & $60 \pm 3$ & 40.5 & 53 & 49 & 59 & 34 & 1 \\
\hline Mahalagou & $41.5-30$ & 36.521 & 101.870 & 4 & 43 & 11 & 3 & 228 & 25 & 40 & 82 & 151 & 3 & $60 \pm 2$ & 41.4 & 54 & 50 & 60 & 35 & 1 \\
\hline Guide & $11.5-2.6$ & 36.1 & 101.3 & 2 & 44 & 8 & 2 & 627 & 26 & 10 & 87 & 125 & 3 & $58 \pm 2$ & 38.6 & 57 & 52 & 62 & 38 & 2 \\
\hline Subei & 20-9 & 39.5 & 94.7 & 356 & 44 & 22 & 2 & 222 & 26 & 10 & 87 & 125 & 3 & $61 \pm 2$ & 41.9 & 63 & 56 & 69 & 44 & 3 \\
\hline \multicolumn{21}{|c|}{ APWP India } \\
\hline Greater India & & & & & & & & & & & & & & & & & & & & \\
\hline Zhongpu & $63-55$ & 28.3 & 88.5 & 357 & 9 & 22 & 3 & 101 & 4 & 60 & 52 & 276 & 6 & $-19 \pm 10$ & -9.8 & 13 & 10 & 18 & 7 & 4 \\
\hline Zhongshan & $71-65$ & 28.3 & 88.5 & 4 & -10 & 12 & 4 & 144 & -5 & 70 & 39 & 280 & 5 & $-39 \pm 7$ & -21.9 & -11 & -14 & -8 & -6 & 4 \\
\hline
\end{tabular}

${ }^{a}$ Data set - paleomagnetic data set from a locality; age - age range of sampled rocks; site location - latitude (Lat) and longitude (Long) of the locality; observed direction - declination (D), inclination (I), precision parameter (k), radius of $95 \%$ confidence circle, number of ChRM directions (n) and derived paleolatitude (Plat); reference pole - age, latitude (Lat), longitude (Long) and radius of $95 \%$ confidence circle ( $\mathrm{A}_{95}$ ) from paleomagnetic Apparent Polar Wander Path for Eurasia or India as indicated [Torsvik et al., 2008]; expected - expected inclination (I), 95\% confidence ( $\Delta \mathrm{I})$ and paleolatitude (Plat) derived from APWP at locality; corrected - shallowing-corrected inclination $\left(\mathrm{I}_{\mathrm{cor}}\right)$ using the method of Tauxe and Kent [2004] with maxima $\left(\mathrm{I}_{+}\right)$and minima $\left(\mathrm{I}_{-}\right)$ of 95\% confidence interval, and associated corrected paleolatitude (Plat); ref. - references: 1 - this study correcting original data from Dupont-Nivet et al. [2008]; 2 - Yan et al. [2006]; 3 - Tauxe [2005] correcting original data from Gilder et al. [2001] with revised age by Wang et al. [2003]; 4 - DupontNivet et al. [2010] correcting original data from Patzelt et al. [1996].

conclude that these scatters represent, and sufficiently average, secular variation.

\section{Compilation of Asian Cenozoic Paleomagnetic Data Sets}

[21] Below we provide a compilation of published Asian paleomagnetic data sets including volcanic rocks and sedimentary rocks that are corrected for the effect of inclination shallowing during deposition and compaction. We exclude all other results obtained from sedimentary rocks. To assess Asian paleolatitudes through time, we compile data sets from so-called 'stable Asia', north of the collision zone (Figure 1).

\subsection{Data Selection From 'Stable Asia'}

\subsubsection{Volcanic Data Sets}

[22] We selected poles from volcanic data across Asia from the Global Paleomagnetic Database (Version 4.6, 2005) following the same criteria as Hankard et al. [2007a]. The search was restricted to volcanic rocks younger than $70 \mathrm{Ma}$ within the frame of Figure 1 (Data Set S1a). ${ }^{1}$

\subsubsection{Sedimentary Data Sets Corrected for Inclination Shallowing}

[23] Inclinations measured in sediments are normally too shallow as a result of deposition and compaction. Several methods have been proposed for correcting this 'inclination shallowing' [e.g., Moreau et al., 2007; Tan et al., 2003; Tauxe, 2005]. The Elongation/Inclination (E/I) correction method developed by Tauxe and Kent [2004], is applicable to data sets with large numbers $(\mathrm{n} \sim 100)$ of independent measurements of PSV. For the Cenozoic, only two Asian mag-

\footnotetext{
${ }^{1}$ Auxiliary materials are available at ftp://ftp.agu.org/apend/tc/ 2008 tc002437.
}

netostratigraphic data sets have been corrected so far, both using the E/I method:

[24] 1. The Subei data set (222 directions) of Gilder et al. [2001] (Figure 2) corrected for inclination shallowing yields (after correction of local rotation from parts of the sampled section) a pole that is concordant with the European APWP (Table 2). Various ages have been attributed to these sediments based on conflicting interpretation of the correlation to the geomagnetic polarity timescale and fossil content (33.5-27 Ma [Yin et al., 2002], 26-19 Ma [Gilder et al., 2001] or 20-9 Ma [Wang et al., 2003]). We choose here the most recent age assignment of $14.5 \mathrm{Ma}$ [Wang et al., 2003].

[25] 2. The Guide basin data set (627 directions, no vertical-axis rotations) dated by magnetostratigraphy (average age $7.1 \mathrm{Ma}$ ), corrected for inclination shallowing, also yields a pole that is concordant with the European APWP [Yan et al., 2006] (Table 2).

[26] 3. In addition to these two data sets, we correct here data sets from a composite Paleogene sedimentary section of the Xining basin, dated by magnetostratigraphy [Dai et al., 2006; Dupont-Nivet et al., 2007]. These sediments yielded primary directions with mean inclinations of $40-50^{\circ}$, clearly shallower than expected from the European APWP $\left(\sim 60^{\circ}\right)$. Anisotropy of Magnetic Susceptibility (AMS) on a selection of 109 samples from these sediments indicates a clear sedimentary fabric (Figure 7) with a nearly vertical minimum axis comparable to other Asian red beds from which detailed rockmagnetic analyses have shown that the inclination of ChRM has undergone $20-30^{\circ}$ inclination shallowing either due to particle shallowing during deposition or post-depositional compaction [Dupont-Nivet et al., 2002; Tan et al., 2003]. The stronger inclination shallowing in these red beds may be expressed by AMS foliation $(\mathrm{k} 2 / \mathrm{k} 3=1.035)$ that is higher than the foliation observed in our Xining red beds $(\mathrm{k} 2 / \mathrm{k} 3=$ 1.014). The likeliness of inclination shallowing affecting our 


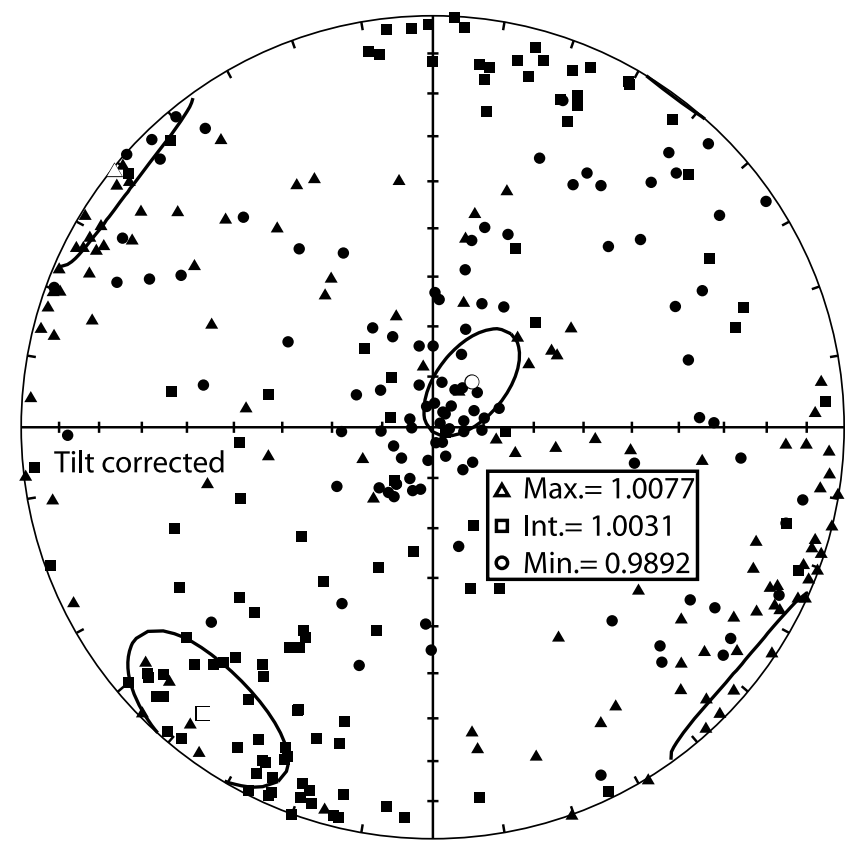

Figure 7. Anisotropy of Magnetic Susceptibility of selected paleomagnetic samples from the Xining sediments shown as principal axis on stereographic projection. Means with confidence ellipse are indicated by open symbols.

rocks along with a large number of ChRM directions make them well-suited for applying the E/I method (Table 2). Due to the long age-span of the section, the results were divided by formations before correction (Chetougou formation, 23$17 \mathrm{Ma}$; Xiejia formation, 30-23 Ma; Mahalagou formation, 41.5-30; Honggou formation 50-41.5 Ma). Only the best quality directions were considered for performing the inclination correction. All directions from line-fits with MAD above $15^{\circ}$ were rejected for the present analysis. In addition, to remove possible transitional directions likely found in these sediments recording a relatively high of number of paleomagnetic reversals, we applied a recursive cut-off method [Vandamme, 1994] on separate sets of reverse and normal polarity populations from each formation. We note that this procedure, excluding only a few directions in each case, did not make a statistically significant difference on the outcome of the E/I method. All data sets pass the reversals test and regional fold test and have not been affected by significant vertical-axis rotations except for the Honggou formation data set [Dupont-Nivet et al., 2008], which was therefore discarded. The E/I correction was applied to the three remaining data sets (Figure 8). Correction resulted in mean inclination slightly steeper $\left(45-55^{\circ}\right)$ but still systematically lower inclinations than expected from the European APWP (Table 2 and Data Set S1a).

\subsection{Calculating the Asian Paleolatitude Discrepancy}

[27] Asian paleolatitudes from our compilation are compared with paleolatitudes predicted by a global synthetic APWP rotated to Eurasian coordinates (Figure 9). From each pole listed in Data Set S1a, the observed paleolatitude was computed and compared with the paleolatitude expected from the APWP for Eurasia of Torsvik et al. [2008] at the presentday site locality. Paleolatitude estimates are thus not affected by possible local vertical-axis rotations. The paleolatitude anomaly ( $\triangle$ PLat) is defined by the observed paleolatitude from Asian data subtracted by the expected paleolatitude from the global synthetic APWP for Eurasia. $\triangle$ PLat is negative (positive) if the observed inclination is shallower (steeper) than the inclination predicted by the global synthetic APWP for Eurasia. To put these results within the context of the India-Asia collision, the paleolatitude anomalies are transferred to the location of the India-Asia suture zone (arbitrarily chosen at $29.0^{\circ} \mathrm{N} ; 88.0^{\circ} \mathrm{E}$ ) such that a negative (positive) paleolatitude anomaly is smaller than (larger than) $29.0^{\circ} \mathrm{N}$. Asian paleolatitudes are then averaged arithmetically over 20 Myr sliding windows at 10 Myr steps so that they can be compared with the APWP for Eurasia and India (Data Set S2a). Remarkably, all calculated Asian paleolatitudes are systematically lower than paleolatitudes expected from the reference European APWP between 50 and $20 \mathrm{Ma}$, but concordant before and after this period as shown in Figure 9. When averaged over 20 Myr sliding windows, Asian paleolatitudes depart significantly from the Eurasian APWP between 50 and $20 \mathrm{Ma}$ (50-30 Ma and 40-20 Ma age windows) with a maximum $12.5^{\circ}$ discrepancy for the $30-50$ Ma window. In the following, we will discuss possible causes for this discrepancy.

\section{Discussion}

[28] The anomalously low Asian paleomagnetic inclinations have been a longstanding problem and were initially rightfully attributed to inclination shallowing due to deposition and compaction of sediments (mostly red beds): Volcanic paleomagnetic data showed inclinations that are up to $30^{\circ}$ steeper than in sediments [Bazhenov and Mickolaichuck, 2002; Gilder et al., 2003; Hankard et al., 2005, 2007a, 2007b; Huang et al., 2005]. However, we confirm here that Cenozoic volcanics yield inclinations that are still systematically $5-10^{\circ}$ shallower than expected by the Eurasian reference APWP. This revives the debate on potential mechanisms to explain the discrepancy. We discuss below the likeliness for (1) systematic bias in Asian data, (2) non-dipole field contributions, and (3) a more southerly position of Asia.

\subsection{Systematic Measurement Bias in Asian Data?}

[29] Systematic, unrecognized southward tilts of volcanic sites may lead to an underestimation of inclination, but this option is unlikely. For the Mongolian localities, north-south tilts are not large enough to fully explain the discrepancy (see the geology of the Gobi Altai above). In addition, independent studies from different working groups in this region converged toward comparable tilt corrections for these sites and reached similar conclusions [Hankard et al., 2007a, 2008; van Hinsbergen et al., 2008]. Furthermore, tilt correction errors as explanation for the discrepancy would need to be restricted to results from 50 to 20 Ma rocks only, but not to results from underlying early Cretaceous to Paleogene rocks that are, according to these studies, concordant with the Eurasian APWP. Moreover, our compilation shows that 
A. Stable Asia: Chetougou Fm. (23-17 Ma)

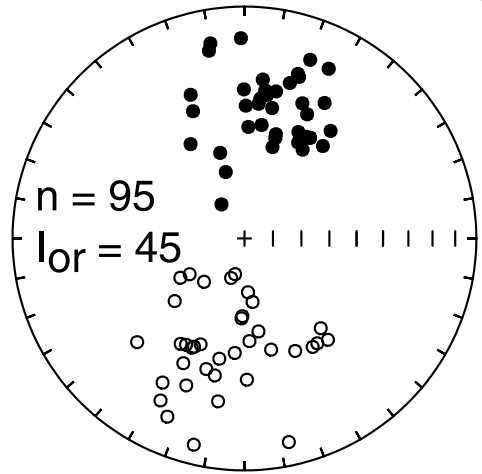

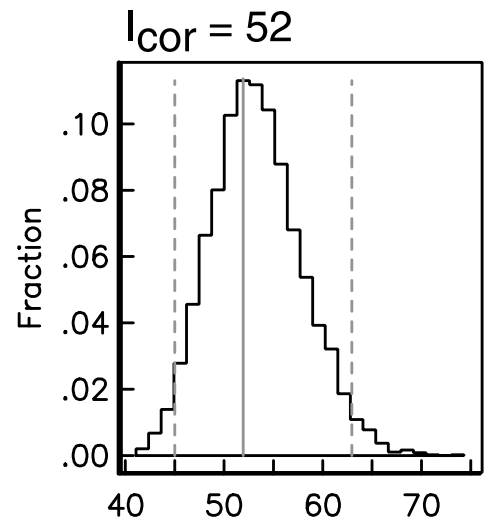

B. Stable Asia: Xiejia Fm. (30-23 Ma)
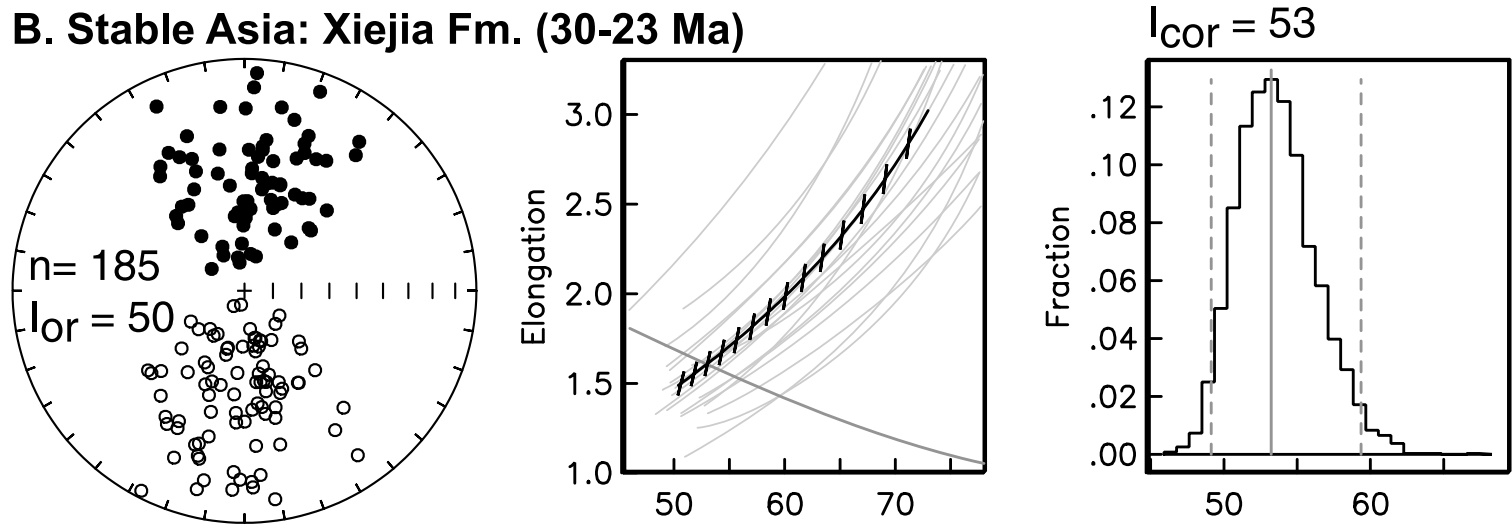

C. Stable Asia: Mahalagou Fm. (41.5-30 Ma)
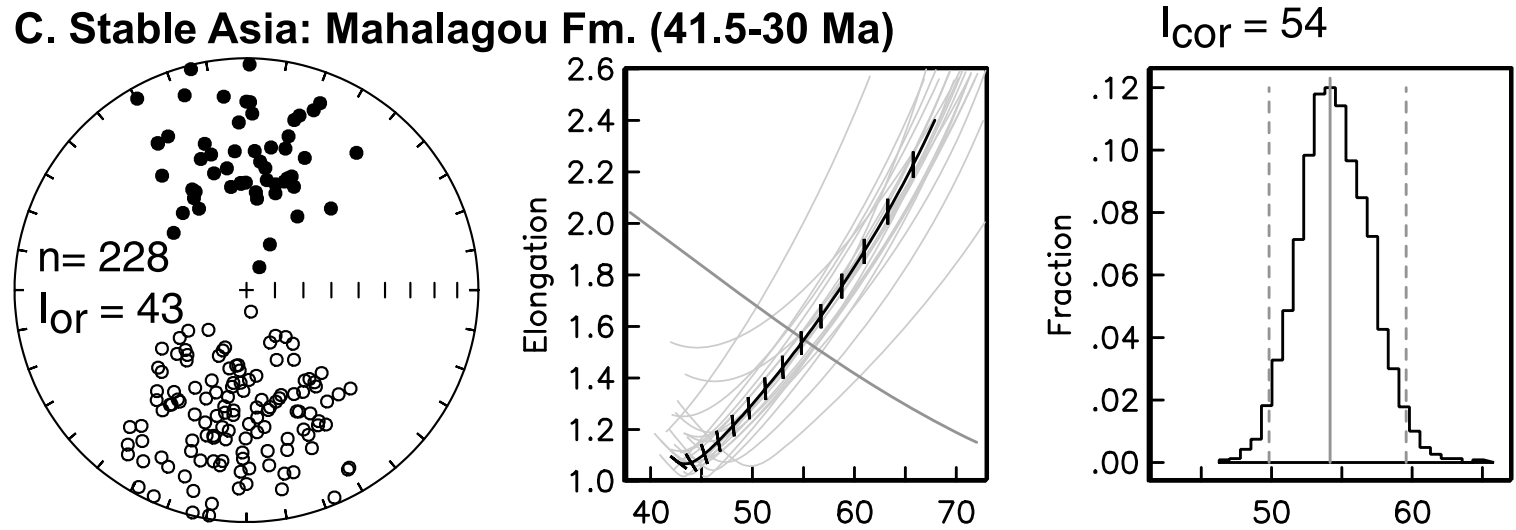

Figure 8. Sedimentary data sets corrected for inclination shallowing using the Elongation-Inclination method of Tauxe and Kent [2004]. (left) Stereographic projection in stratigraphic coordinates of $n$ individual ChRM directions. Ior is original mean inclination before correction. (middle) Thick black line is the range of elongation-inclination obtained upon applying a range of flattening factors on the original data set. Thick gray line is expected inclination-elongation pairs according to Tauxe and Kent [2004]. The intersection defines the corrected inclination. (right) Probability histogram of corrected inclination (Icor) from bootstrap analysis. Dashed lines indicate $95 \%$ confidence interval.

the discrepancy is also observed in results from rocks of the same age in other regions with different tectonic settings and tilts, and we conclude that tilt correction errors form an unlikely explanation.

[30] Systematic under-correction of inclination shallowing in $~ 50-20 \mathrm{Ma}$ sediments arising from the E/I method of Tauxe and Kent [2004] is also found unlikely. Corrected data sets are still scarce, but yield consistently low inclinations after correction for data sets from $20 \mathrm{Ma}$ and older rocks, and inclinations concordant with the expected for $20 \mathrm{Ma}$ and younger rocks. Moreover, application of cut-offs such as Vandamme [1994] does not significantly change the corrected inclinations, suggesting that the correction method is not sensitive to outliers.

[31] Finally, it is remarkable that comparable inclinations are obtained from both lavas and inclination shallowing- 
A. Asian data vs. APWP T08

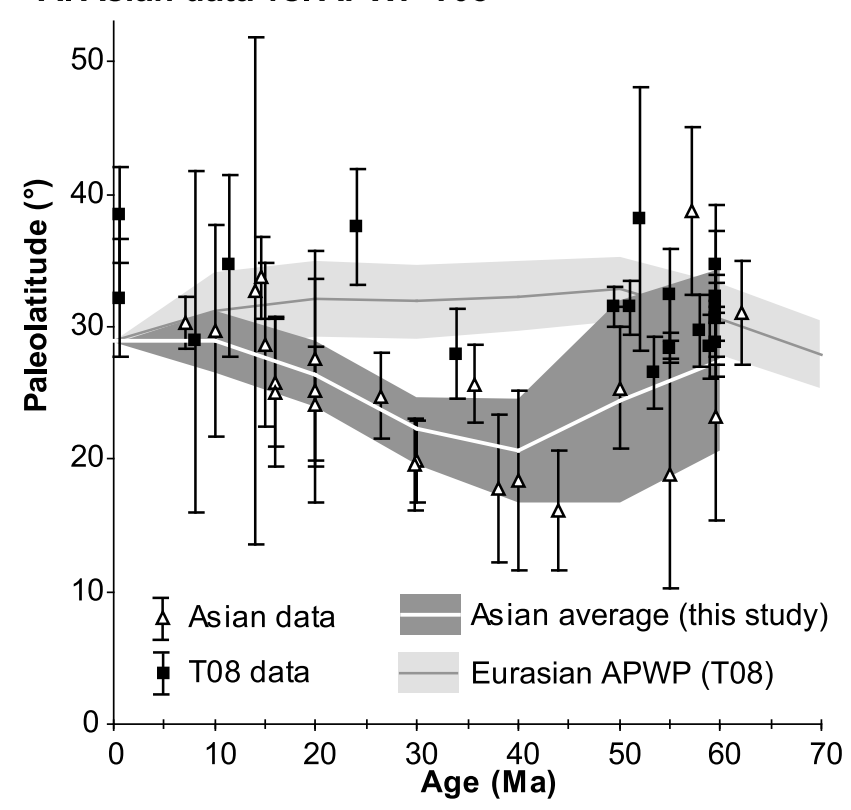

B. Asian data vs. APWP BC02

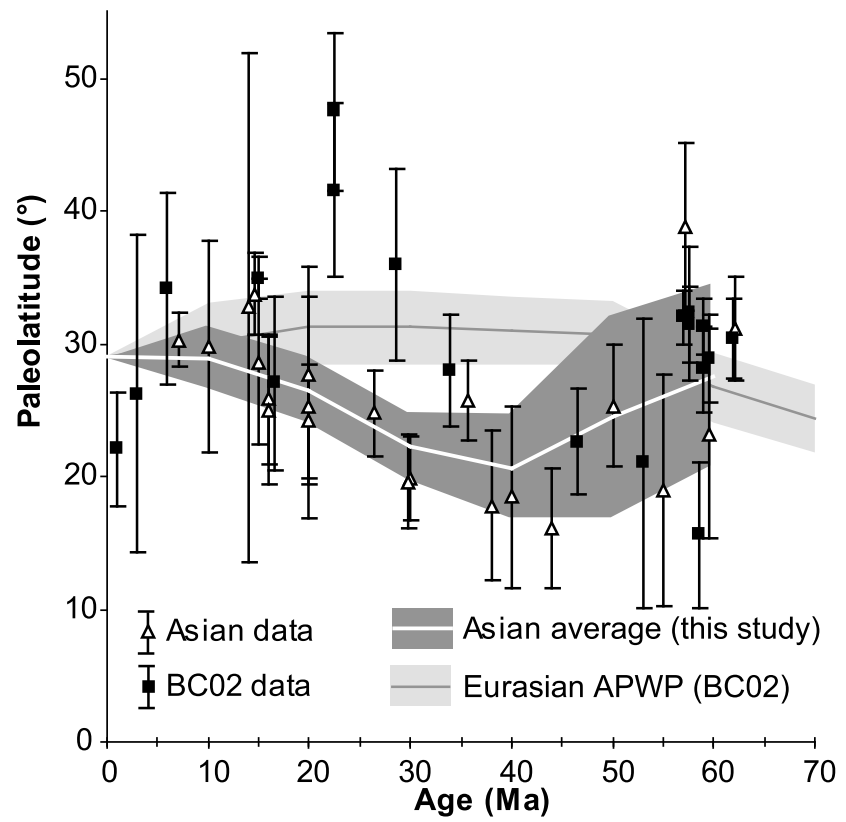

Figure 9. Asian average paleolatitudes through time calculated using this study's compiled data (open triangles) from volcanics and shallowing-corrected sediments (Data Set S1a) compared to Apparent Polar Wander Paths for Eurasia of (a) Torsvik et al. [2008] (APWP T08) and (b) Besse and Courtillot [2002] (APWP BC02) with associated Eurasian data points (black squares) on which these APWPs are based.

corrected sediments, from different regions, and different ages between $\sim 50$ and $\sim 20 \mathrm{Ma}$, demonstrating the robustness of the systematic deviation of Asian data when compared with directions predicted by the Eurasian APWP.

\subsection{Non-dipole Field Contributions?}

[32] Paleolatitudes are calculated from measured paleomagnetic inclinations under the fundamental assumption that the time-averaged geomagnetic field results from a geocentric axial dipole (GAD). However, concerns exist about the validity of the GAD hypothesis, especially due to potential octupole (G3) contributions [Chauvin et al., 1996; Si and Van der Voo, 2001; Torsvik et al., 2001; Torsvik and Van der Voo, 2002; Torsvik et al., 2002; Van der Voo and Torsvik, 2001]. Estimating ancient non-dipole field components is difficult, but it has been shown that systematic Tertiary discrepancies between moving hot spot reference frames and paleomagnetic reference frames can be reconciled with G3 contributions of 8-10\% [Torsvik et al., 2001, 2002]. With direct relevance to this study, Si and Van der Voo [2001] compared low Tertiary inclinations in central Asia (then including also uncorrected sediment-based directions) with those predicted from the Eurasian APWP, and found that the paleolatitude discrepancy could be eliminated with a mean G3 greater than 6\%. Our Asian data set and our reference synthetic APWP [Torsvik et al., 2008] differ from those of Si and Van der Voo [2001], and we find that no single G3 value can perfectly match Asian data to the Eurasian APWP. If the discrepancy between our compiled Asian data and the APWP would be entirely attributable to G3, we would need time-dependent G3 values [Torsvik and Van der Voo, 2002]. By searching for the optimum fit of Asian data to the global APWP in $5 \mathrm{Ma}$ bins, and recalculating the global APWP and the Asian data in $2 \% \mathrm{G} 3$ increments gives the following solution: (1) G3 would be close to zero since $15 \mathrm{Ma},(2)$ a steady increase in $\mathrm{G} 3$ from 15 Ma back to 40-50 Ma, with G3 peak values of $14-16 \%$, and (3) declining G3 contributions back to the late Cretaceous (Figure $10 \mathrm{~b}$ and Data Set S1b and S2b).

[33] The average $\mathrm{G} 3$ before $\sim 15 \mathrm{Ma}$ is thus estimated to $8 \%$ but some of these G3 values are significantly higher than previous estimates for the Cenozoic (6-10\%) or the octupole contributions of $5 \%$ found for the Matuyama chron [see Johnson et al., 2008, and references therein]. Also, it is unlikely that such long periods of high G3 values $(>10 \%)$ have gone unnoticed in Cenozoic data set from other parts of the world since G3 is a zonal term of the spherical harmonic expansion of the field. Therefore, we argue that non-dipolar fields cannot fully explain the Asian paleolatitude discrepancy but a partial ( $\sim 5 \%)$ G3 contribution is not unlikely.

\subsection{Southerly Asian Latitude?}

[34] Because the 50-20 Ma discrepancy can probably not (entirely) result from G3 contributions or flaws in the data, Asia must have had a lower latitude in this time window than suggested by the APWP. However, this suggests that there is a bias in either the currently used paleomagnetic reference frames and/or in the plate circuits. The APWP is based on two main data sets [Cox and Hart, 1986]. First, the relative position of plates is precisely determined by global plate circuits constructed using Euler poles obtained from retrofitting marine magnetic anomalies (assuming plate rigidity). Second, the past positions of the entire plate circuit with respect to the earth spin axis are determined by a selection of 
A. Asian motion only

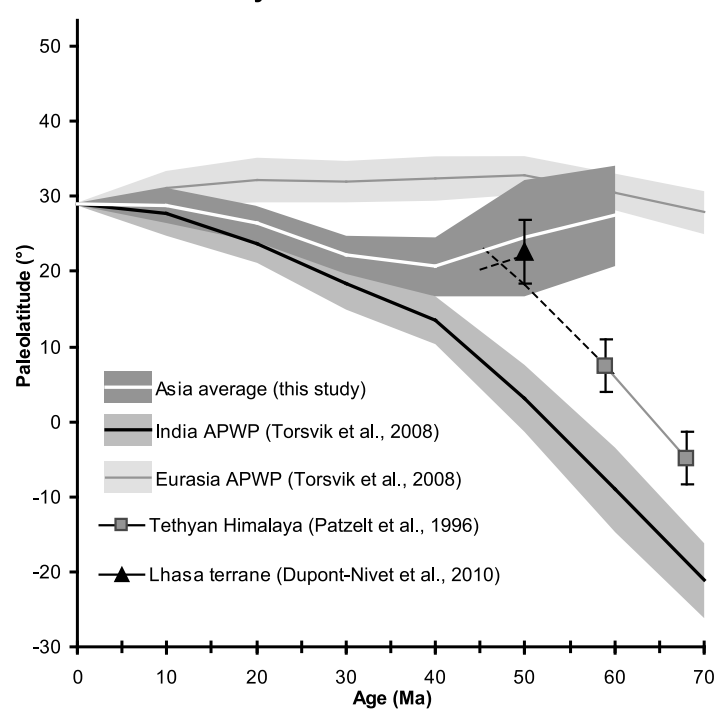

B. Time dependant $\mathbf{G} 3$ only

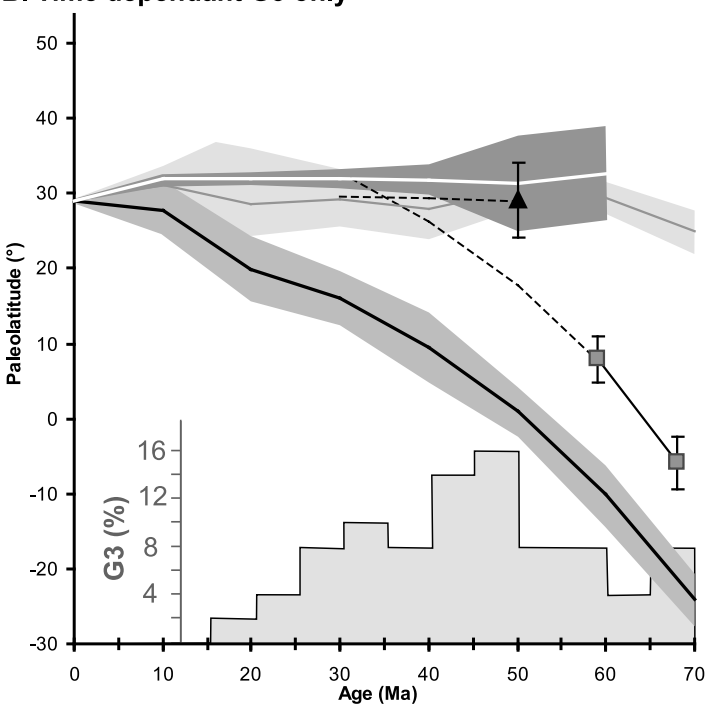

C. Hybrid path

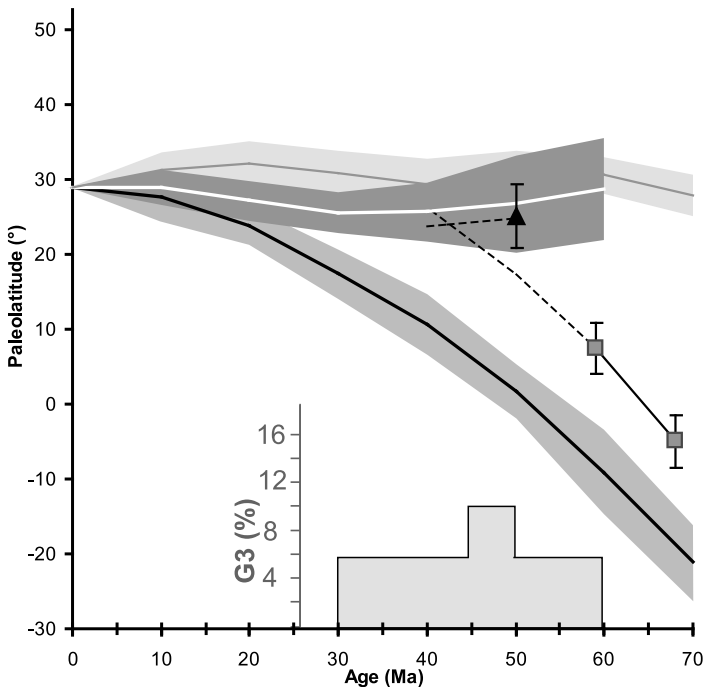

paleomagnetic poles from all continents. These poles are rotated using the Euler poles defined by the plate circuit into coordinates of a given tectonic plate, to construct a synthetic APWP for that plate [Besse and Courtillot, 2002; Schettino and Scotese, 2005; Torsvik et al., 2008]. In other words: the APWP for India or Eurasia is based on exactly the same paleomagnetic data set as the APWP of all other continents. Interestingly, the Cenozoic APWP paths of Torsvik et al. [2008] and Besse and Courtillot [2002] contain no paleomagnetic data from India and no paleomagnetic data from Asia (Figure 9). A more southerly position of Asia than predicted by the APWP would thus either require that Eurasia is not a single rigid plate, that Asia's position in the global plate circuit is inaccurate, or that the global APWP is imperfect. We review arguments for and against these possibilities below.

\subsubsection{Non-rigidity of Eurasia?}

[35] Given the significant difference between the Eurasian APWP and Asian poles, it has been previously proposed that non-rigidity of Eurasia may explain the discrepancy between Asian and European paleomagnetic inclinations [Cogné et al., 1999; Hankard et al., 2007a]. To fully resolve the Asian inclination discrepancy presented here, this hypothesis requires that central Asia rotated $12.5^{\circ}$ southward with respect to Europe (accommodating a total $\sim 1400 \mathrm{~km}$ respective latitudinal motion) between $\sim 60$ and $\sim 40 \mathrm{Ma}$, and then moved back northward since $\sim 40$ Ma over a similar angular distance (Figure 10a). To accommodate these motions fully, it has been suggested that they can be distributed in multiple Cenozoic reactivations of ancient strikeslip zones such as the Tornquist-Tesseyre line in Europe, and the Ural mountain ranges [Cogné et al., 1999; Hankard et al., 2007a]. We find difficult to envisage that the required Cenozoic motions would not have been noticed until now. For comparison, the extensive Gobi Altai and Mongolian Altai mountain belts were probably produced by only some tens of kilometers of cumulative strike-slip motion [Cunningham, 2005]. Eurasian non-rigidity would also require the plate circuit to be inaccurate.

\subsubsection{Inaccuracy of Plate Circuits?}

[36] Inaccuracies in plate circuits could allow (1) nonrigidity of Eurasia (unlikely, see above) or (2) repositioning the entire Eurasian plate with respect to other plates [Gordon, 1998]. Two studies have recently investigated the position of

Figure 10. Same as Figure 9 with addition of APWP for India and paleolatitudes provided by paleomagnetic results from Paleogene rocks of the Tethyan Himalaya and the Lhasa terranes found today on either side of the suture zone. Dashed line extrapolations indicate most likely locus of collision between these terranes. (a) Assuming the full latitudinal discrepancy between the Asian average and the APWP for Eurasia is associated to Asian latitudinal motion (unlikely, see text). (b) Assuming the full discrepancy is due to timedependant octopular field contribution (G3) to Asian data optimized to fit the APWP in 5 Myr windows (unlikely, see text). (c) Hybrid latitudinal path for Asia optimized with the lowest possible time-dependant octopular contribution assuming that inaccuracies in the APWP did not exceed $5^{\circ}$. 
Eurasia with respect to North America through the North Atlantic and Arctic plate circuits, one of the best constrained plate reconstructions [Alvey et al., 2008; Gaina et al., 2002]. The non-rigidity of Eurasia is not favored by the observed continuity of well-preserved magnetic isochrones in the arctic directly north Eurasian margin associated with the opening of the Eurasian Basin since $\sim 54 \mathrm{Ma}$ [Alvey et al., 2008]. The error in the position of the Eurasian plate with respect to North America is typically well within $1^{\circ}$. The differences in the various Eurasia-North America finite rotation pole models may lead to variations in stage rotations and predicted relative motions of less than $3^{\circ}$ [Gaina et al., 2002]. These uncertainties are larger for the early Cenozoic interval partly due to error propagation and larger time intervals between analyzed reversals but, although a partial contribution cannot be ruled out, it is highly unlikely that plate circuit uncertainties are anywhere near the $\sim 10^{\circ}$ discrepancy.

\subsubsection{Inaccuracy of the APWP?}

[37] The accuracy of the synthetic global APWP dictated by the quality of paleomagnetic data and age constraints, and the data density in a given time interval. Interestingly, the APWP is poorly constrained in Paleogene time by scarcity in the global paleopole database, especially for Eurasia and India. Many of these poles have poor age control, and were derived from pre-1980 studies [Riisager et al., 2002]. Moreover, because of the controversy on Asian inclinations, Besse and Courtillot [2002] as well as Torsvik et al. [2008] rejected Asian data from the construction of their global synthetic APWP leaving only poles from western Europe, thousands of kilometers from Asia.

[38] We review below the three synthetic APWPs of Schettino and Scotese [2005], Torsvik et al. [2008] and Besse and Courtillot [2002]. Schettino and Scotese [2005] base their 50-20 Ma APWP on the largest number of data sets of the three (47 poles globally, including eight Eurasian after their filtering) according to very permissive acceptance criteria for data selection (automatic scanning of the global paleomagnetic database including numerous poles later deemed unreliable by Torsvik et al. [2008]). However, their subsequent spline fitting procedure over large time intervals $(\sim 50 \mathrm{Ma})$ provides such a strong smoothing that relatively small variations $\left(5-10^{\circ}\right)$ such as observed in the Asian data reported here disappear. The APWP of Torsvik et al. [2008] for the 50 to $20 \mathrm{Ma}$ interval is based on 26 poles globally, of which only three are from Eurasia (all from Europe with associated age uncertainty ranging from \pm 5 to $\pm 25 \mathrm{Ma}$; Figure 9a [see Torsvik et al., 2008, Table 3]). Similarly, the 50-20 Ma synthetic APWP of Besse and Courtillot [2002] is based on 26 (mainly other) poles globally, of which five are from Eurasia (all from Europe with associated age uncertainty ranging from \pm 13 to $\pm 25 \mathrm{Ma}$; Figure $9 \mathrm{~b}$ [see Besse and Courtillot, 2002, Table 1]). Immediately apparent is the paucity, the large differences between, and the poor age control of the selected European poles in the 50-20 Ma period when compared with the now available Asian data. This clearly shows that the position of Eurasia is determined primarily by poles that are not from Eurasia but mostly from North America and Africa. Ultimately, the precision of the Eurasian (/global) APWP is thus dictated by the quality of these indigenous poles and the plate motion circuits between
Europe-North America (North Atlantic) and North AmericaAfrica (Central Atlantic). Because most poles that determine the 'Eurasian' APWP were derived $\sim 90^{\circ}$ west of the IndiaAsia collision zone, a small uncertainty in declination of the measured sites translates in an almost equal uncertainty in predicted inclination in Tibet.

[39] Given the error accumulation associated to the indirect construction of the Eurasian APWP explained above, we consider that a small $\left(<5^{\circ}\right)$ latitudinal discrepancy between the Asian data and the synthetic APWP may be attributed to inaccuracies in the APWP. Still, a $10^{\circ}$ bias is a lot to go undetected, especially because this bias must be applied to other plates linked to Eurasia through the global plate circuit.

\subsection{Conclusion: A Hybrid APWP for Asia}

[40] From the review and analyses presented above, two potential explanations are identified to partly explain the Asian paleolatitude discrepancy (1) Asia was indeed located further to the south than expected by the APWP at the time of the collision with India and/or (2) long-standing timedependent octopular contributions to the magnetic field may decrease the Asian inclinations. As discussed above, fully explaining this discrepancy by only one of these proposed mechanisms would imply either unrealistically large inaccuracies in the APWP, or unrealistically large octupolar field contributions. A combination (rather than only one) of these mechanisms is thus explored in the following. Because their respective contributions cannot be quantified at this stage, we propose based on the principle of least astonishment, a hybrid APWP for Asia by allowing for reasonable ( $5 \%)$ time-dependant non-dipolar contributions (as found in the global compilation of 0-5 Ma lavas [Johnson et al., 2008; Merril et al., 1998]) and slightly $\left(\sim 5^{\circ}\right)$ more southerly Asian position that may be attributed to inaccuracies in the APWP (see discussion above). We first applied an octopular contribution of 5\% for the 55-25 Ma period with the highest latitudinal discrepancy. This reduces the discrepancy to $<5^{\circ}$ except for the 45-40 Ma interval requiring an octupolar contribution of $10 \%$ to reduce the discrepancy to $<5^{\circ}$ (Figure $10 \mathrm{c}$ and Data Set S1c and S2c). We thus constructed a hybrid latitudinal path for Asia allowing the lowest possible timedependant octopular contribution assuming that inaccuracies in the APWP did not exceed $5^{\circ}$. We explore below the tectonic implications of this hybrid path on the India-Asia collision.

\section{Implications for the India-Asia Collision}

[41] Paleomagnetic data are especially important to provide independent constraints on the paleolatitudes through time of the terranes found on either side of the India-Asia suture (the Lhasa terrane to the North and the Tethyan Himalayas to the South). Using the most recent and complete data sets and revisions on the paleolatitudes of these terranes (see data of Dupont-Nivet et al. [2010] that includes and supersedes Tan et al. [2010]), the obtained $22.8 \pm 4.2^{\circ} \mathrm{N}$ paleolatitude at which these terranes start to overlap implies collision occurring by $46 \pm 8 \mathrm{Ma}$. When compared with the respective paleolatitudes of India and Asia derived from the APWP for Eurasia, these constraints imply $2900 \pm 600 \mathrm{~km}$ subsequent latitudinal convergence between India and Asia divided into 
$1100 \pm 500 \mathrm{~km}$ within Asia and $1800 \pm 700 \mathrm{~km}$ within India. However, we show here that the APWP is not consistent with Asian data sets. Using the hybrid path proposed above implies lower latitudes for Asia $\left(27.4 \pm 7.1^{\circ} \mathrm{N}\right.$ at $\left.50 \mathrm{Ma}\right)$ in the hybrid path (Data Set S1c and Figure 10c) rather than $32.9 \pm$ $2.6^{\circ} \mathrm{N}$ for the APWP for Eurasia (Data Set S1a and Figure 10a). To estimate intra-Asian convergence, this is compared to the latitude of the Lhasa terrane at 54-47 Ma of Dupont-Nivet et al. [2010] that is corrected from $22.8^{\circ} \pm$ $4.2^{\circ} \mathrm{N}$ to $25.1 \pm 4.2^{\circ} \mathrm{N}$ with the $5 \% \mathrm{G} 3$ contribution according to our hybrid model (Figure 10c and Data Set S1c). In turn, this implies only $200 \pm 900 \mathrm{~km}$ of latitudinal convergence north of the suture zone within Asia since $50 \mathrm{Ma}$. This is in much better agreement with documented deformation of the collision zone accounting for no more than 200-300 km of Miocene and younger N-S shortening found essentially in the periphery of the Tibetan Plateau in the Tien Shan, Qilian Shan - Nan Shan and Kunlun Shan [Avouac and Tapponnier, 1993; Métivier et al., 1999; Meyer et al., 1998; Ritts et al., 2008]. In addition, there is growing evidence for early deformation within the central and northern Tibetan Plateau that could account for an additional $100-200 \mathrm{~km}$ of $\mathrm{N}-\mathrm{S}$ shortening [Kapp et al., 2007, 2005]. Because the latitude of the Lhasa terrane is shifted slightly to the North due correction of the $5 \%$ G3 contribution, the age of the collision based on the overlap with the Tethyan Himalaya latitude becomes slightly younger (Figure 10c) but not statistically different than previously estimated (46 $\pm 8 \mathrm{Ma}$ ) by Dupont-Nivet et al. [2010]. Finally, the total India-Asia convergence and the post collisional convergence within India are difficult to assess in our hybrid model because it is not clear how much of the Asian low latitude bias can be attributed to inaccuracy in the APWP or in the plate circuit respectively (a maximum of $\sim 5^{\circ}$ after the G3 correction has been applied). It is important to realize here that the relative convergence between Asia and India is determined through the plate circuit, and is independent of paleomagnetic poles obtained from these continents. Therefore, the India-Asia convergence remains the same if the $5^{\circ}$ bias is attributed only to inaccuracy in the APWP but will change if the plate circuit is inaccurate. In effect, when Ali and Aitchison [2006] propose a new pole for Eurasia to estimate the age of the collision by comparing to the APWP for India, they infer that the plate circuit is inaccurate but not the APWP. In contrast, assuming that the $5^{\circ}$ bias in Asia is fully from APWP inaccuracy implies that this $5^{\circ}$ must also be applied to India. In that case, the India-Asia convergence would remains the same but this would make the latitudinal distance between India and the Tethyan Himalayas $5^{\circ}$ $(550 \mathrm{~km})$ larger than the previously estimated $1800 \pm 600 \mathrm{~km}$ which can therefore be considered a minimum estimate. This is much larger than can be accounted for by crustal shortening estimates along the Himalayan arc from Pakistan to Sikkim summing up to a total $\sim 700 \mathrm{~km}$ minimum shortening in the fold-thrust belt occurring mostly after 25-20 Ma [DeCelles et al., 2002; Long et al., 2010]. This has led previous researchers to suggest that Greater India (between the Tethyan Himalayas and India) may have consisted of thinned continental [Acton, 1999] or even oceanic lithosphere allowing for lithosphere bypassing the subduction zone [Dupont-Nivet et al., 2010]. Alternatively, the mismatch between Indian convergence and Himalayan shortening has led to proposals that the $50 \mathrm{Ma}$ event is related to collision of an island arc with Asia preceding a much younger $(<35 \mathrm{Ma})$ India-Asia collision, and that a large portion of oceanic crust being preserved north of Greater India at $50 \mathrm{Ma}$ [Aitchison et al., 2007]. Evidently, more paleomagnetic data north and south of the suture zone, notably from the Himalayas, are required to further test these hypotheses and reduce the error bars on these estimates.

\section{Conclusions}

[42] Asian paleolatitudes are consistently lower than predicted by Apparent Polar Wander Paths (APWPs). We provide new paleomagnetic results from volcanic rocks from Mongolia, and sedimentary data sets from China corrected for inclination shallowing, which together with compiled reliable Asian data sets (including only results from volcanic rocks and inclination-corrected sediments) confirm that Asian paleolatitudes are 5-10 $0^{\circ}$ lower than predicted by the APWP in the 50-20 Ma period. Two explanations are investigated: (1) Asian was indeed $>1000 \mathrm{~km}$ further south than predicted by the APWP (due to Eurasian non-rigidity, inaccurate plate circuit for Eurasia, or inaccurate global APWP) or (2) large and long-standing time dependent octupolar contributions (up to $16 \%$ ) to the geomagnetic field. We conclude that neither option can realistically explain the observed inclination anomaly. However, a combination of octupolar contributions and inaccuracies in the global APWP can reasonably have produced the observed latitudinal discrepancy taking the typical APWP uncertainties $\left(<5^{\circ}\right)$ and G3 values $(5 \%)$ into account. We therefore constructed a hybrid paleolatitudinal path for Asia, allowing the lowest possible time-dependant octopular contributions under the assumption that the APWP inaccuracy on Asian latitudinal motion does not exceed $5^{\circ}$. Reconstruction of the India-Asia collision according to this hybrid path, together with the selected paleomagnetic data from the collision zone imply Asian intracontinental shortening occurred since the collision in agreement with crustal shortening estimates.

\section{Epilogue}

[43] In this paper, we illustrate how APWPs are used to place very important quantitative constraints on amounts and rates of shortening accommodated in orogens, as well as to identify ages of major tectonic events. These arguments eventually lie at the basis of spectacular geodynamic and tectonic processes, such as tectonic extrusion, the possibility of many hundreds of kilometers of continental subduction, and consumption of well over $1000 \mathrm{~km}$ of a continental overriding plate during ocean closure and continentcontinent collision. However, the synthetic APWP is based on quite low amounts of data, for, in the last few decades, paleomagnetic research has mainly focused on resolving more detailed tectonic problems concerning rotations, or paleopositions of small terranes incorporated in orogens, and much less on stable cratons, the position and motion of which is assumed as well-constrained. Therefore, APWPs are largely based on old data sets, the age and paleomagnetic 
analysis reported in which to an increasingly smaller degree do no longer fit the standards we require today. As a result, sliding windows of 10,20 or even $50 \mathrm{Ma}$ are used, filtering out 'details' in plate motions. In this paper, we compile existing and report new data for the early Cenozoic of Asia and show that these strongly differ from the synthetic APWPs. As we presented here, this difference has major repercussions for the Indo-Asia collision, and thus also for the geodynamic and tectonic scenarios that were developed here. The main conclusion we have to draw is that the existing synthetic APWPs do not provide reliable quantitative constraints on a 'detailed' time-scale of 10 to $20 \mathrm{Ma}$, which is an essential timescale in the analysis of orogenic processes and associated geodynamics. We therefore would like to interest the paleomagnetic community to focus at least part of their future efforts on the collection of high-resolution, well-dated paleomagnetic data from the stable cratons, as identification and further analysis of (here: tectonic) anomalies strongly relies on a reliable reference frame.

[44] Acknowledgments. This research was funded by the Netherland Organization for Scientific Research (NWO) to G.D.-N. and D.J.J.v.H., the UK NERC grant NER/D/S/2003/00671NERC to D.J.J.v.H., and NFR Petromaks grant to T.H.T. We thank Dickson W. Cunningham for discussions, Gijs Straathof for the precious help in the field and lab, and Ahmet Peynircioğlu for drafting figures. We thank two anonymous and insightful reviewers and Todd Ehlers (Editor) for their comments and suggestions. D.J.J.v.H. and T.H.T. acknowledge financial support of StatOil (SPlates Project).

\section{References}

Acton, G. D. (1999), Apparent polar wander of India since the Cretaceous with implications for regional tectonics and true polar wander, in The Indian Subcontinent and Gondwana: A Palaeomagnetic and Rock Magnetic Perspective, Memoir, vol. 44, edited by T. Radhakrishna and J. D. A. Piper, pp. 129-175, Geol. Soc. of India, Bangalore, India.

Aitchison, J. C., J. R. Ali, and A. M. Davis (2007), When and where did India and Asia collide?, J. Geophys. Res., 112, B05423, doi:10.1029/ 2006JB004706.

Aitchison, J. C., J. R. Ali, and A. M. Davis (2008), Reply to comment by Eduardo Garzanti on "When and where did India and Asia collide?," J. Geophys Res., 113, B04412, doi:10.1029/2007JB005431.

Ali, J. R., and J. C. Aitchison (2006), Positioning Paleogene Eurasia problem: Solution for $60-50 \mathrm{Ma}$ and broader tectonic implications, Earth Planet. Sci. Lett., 251, 148-155, doi:10.1016/j.eps1.2006.09. 003.

Alvey, A., C. Gaina, N. J. Kusznir, and T. H. Torsvik (2008), Integrated crustal thickness mapping and plate reconstructions for the high Arctic, Earth Planet. Sci. Lett., 274, 310-321, doi:10.1016/j. eps1.2008.07.036.

Avouac, J. P., and P. Tapponnier (1993), Kinematic model of active deformation in central Asia, Geophys. Res. Lett., 20(10), 895-898, doi:10.1029/ 93GL00128.

Barry, T. L., A. D. Saunders, P. D. Kempton, B. F. Windley, M. S. Pringle, D. Dorjnamjaa, and S. Saandar (2003), Petrogenesis of Cenozoic basalts from Mongolia: Evidence for the role of asthenospheric versus metasomatized lithospheric mantle sources, J. Petrol., 44, 55-91, doi:10.1093/petrology/44.1.55.

Bayasgalan, A., J. Jackson, J.-F. Ritz, and S. Carretier (1999), Field examples of strike-slip fault terminations in Mongolia and their tectonic significance, Tectonics, 18, 394 411, doi:10.1029/1999TC900007.

Bazhenov, M. L., and A. V. Mickolaichuck (2002), Paleomagnetism of Paleogene basalts from the Tien Shan, Kyrgyzstan: Rigid Eurasia and dipole geomagnetic field, Earth Planet. Sci. Lett., 195, 155166, doi:10.1016/S0012-821X(01)00586-6.

Besse, J., and V. Courtillot (2002), Apparent and true polar wander and the geometry of the geomagnetic field in the last $200 \mathrm{Myr}, J$. Geophys. Res., 107(B11), 2300, doi:10.1029/2000JB000050.

Biggin, A. J., D. J. J. van Hinsbergen, C. G. Langereis, G. B. Straathof, and M. H. L. Deenen (2008), Geomagnetic secular variation in the Cretaceous Normal Superchron and in the Jurassic, Phys. Earth Planet. Inter., 169, 3-19, doi:10.1016/j.pepi.2008. 07.004.

Butler, R. F. (1992), Paleomagnetism: Magnetic Domains to Geologic Terranes, 238 pp., Blackwell Sci., Boston, Mass.
Chauvin, A., H. Perroud, and M. L. Bazhenov (1996), Anomalous low palaeomagnetic inclinations from Oligocene-Lower Miocene red beds of the south west Tien Shan, central Asia, Geophys. J. Int. 126, 303-313, doi:10.1111/j.1365-246X.1996. tb05293.x.

Cogné, J. P., N. Halim, Y. Chen, and V. Courtillot (1999), Resolving the problem of shallow magnetizations of Tertiary age in Asia: Insights from paleomagnetic data from the Qiangtang, Kunlun, and Qaidam blocks (Tibet, China), and a new hypothesis, J. Geophys. Res., 104(B8), 17,715-17,734, doi:10.1029/1999JB900153.

Copley, A., J.-P. Avouac, and J.-Y. Royer (2010), IndiaAsia collision and the Cenozoic slowdown of the Indian plate: Implications for the forces driving plate motions, J. Geophys. Res., 115, B03410, doi:10.1029/2009JB006634.

Cox, A., and R. B. Hart (1986), Plate Tectonics: How It Works, Blackwell Sci., Palo Alto, Calif.

Cunningham, W. D. (2005), Active intracontinental transpressional mountain building in the Mongolian Altai: Defining a new class of orogen, Earth Planet Sci. Lett., 240, 436-444, doi:10.1016/j.epsl.2005. 09.013.

Cunningham, W. D. (2007), Structural and topographic characteristics of restraining bend mountain ranges of the Altai, Gobi Altai and easternmost Tien Shan, in Tectonics of Strike-Slip Restraining and Releasing Bends, edited by W. D. Cunningham and P. Mann, Geol. Soc. Spec. Publ., 290, 219-237.

Cunningham, W. D., B. F. Windley, D. Dornjnamjaa, D. Badamgarav, and M. Saander (1996), Late Cenozoic transpression in southwestern Mongolia and the Gobi-Altai-Tien Shan connection, Earth Planet. Sci. Lett., 140, 67-81, doi:10.1016/0012-821X(96) 00048-9.

Cunningham, W. D., B. F. Windley, L. A. Owen, T. Barry, D. Dornjnamjaa, and J. Badamgarav (1997), Geometry and style of partitioned deformation within a late Cenozoic transpressional zone in the eastern Gobi Altai Mountains, Mongolia, Tectonophysics, 277, 285-306, doi:10.1016/S0040-1951 (97)00034-6

Dai, S., X. Fang, G. Dupont-Nivet, C. Song, J. Gao, W. Krijgsman, C. Langereis, and W. Zhang (2006), Magnetostratigraphy of Cenozoic sediments from the Xining Basin: Tectonic implications for the northeastern Tibetan Plateau, J. Geophys. Res., 111, B11102, doi:10.1029/2005JB004187.

Dankers, P. H. M., and J. D. A. Zijderveld (1981), Alternating field demagnetization of rocks, and the problem of gyromagnetic remanence, Earth Planet. Sci. Lett., 53, 89-92, doi:10.1016/0012-821X(81) 90029-7.

DeCelles, P. G., D. M. Robinson, and G. Zandt (2002) Implications of shortening in the Himalayan fold- thrust belt for uplift of the Tibetan Plateau, Tectonics, 2l(6), 1062, doi:10.1029/2001TC001322.

Devyatkin, Y. V., and S. B. Smelov (1980), Position of basalts in the Cenozoic sedimentary sequence of Mongolia, Int. Geol. Rev., 22(3), 307-317, doi:10.1080/00206818209466888.

Dunlop, D., and Ö. Özdemir (1997), Rock Magnetism: Fundamentals and Frontiers, 573 pp., doi:10.1017/ CBO9780511612794, Cambridge Univ. Press, Cambridge, U. K.

Dupont-Nivet, G., Z. Guo, R. F. Butler, and C. Jia (2002), Discordant paleomagnetic direction in Miocene rocks from the central Tarim Basin: Evidence for local deformation and inclination shallowing, Earth Planet. Sci. Lett., 199, 473-482, doi:10.1016/S0012-821X(02)00566-6.

Dupont-Nivet, G., W. Krijgsman, C. G. Langereis, H. A. Abels, S. Dai, and X. Fang (2007), Tibetan plateau aridification linked to global cooling at the Eocene-Oligocene transition, Nature, 445, 635-638, doi:10.1038/nature05516.

Dupont-Nivet, G., S. Dai, X. Fang, W. Krijgsman, V. Erens, M. Reitsma, and C. Langereis (2008), Timing and distribution of tectonic rotations in the northeastern Tibetan Plateau, in Investigations Into the Tectonics of the Tibetan Plateau, edited by B. C. Burchfiel and E. Wang, Spec. Pap. Geol. Soc. Am., 444, 73-87.

Dupont-Nivet, G., P. C. Lippert, D. J. J. van Hinsbergen, M. J. M. Meijers, and P. Kapp (2010), Palaeolatitude and age of the Indo-Asia collision: Palaeomagnetic constraints, Geophys. J. Int., 182, 1189-1198, doi:10.1111/j.1365-246X.2010.04697.x.

Fisher, R. A. (1953), Dispersion on a sphere, Proc. $R$. Soc. London, Ser. A, 217, 295-305, doi:10.1098/ rspa.1953.0064

Gaina, C., W. R. Roest, and R. D. Müller (2002), Late Cretaceous-Cenozoic deformation of northeast Asia, Earth Planet. Sci. Lett., 197, 273-286, doi:10.1016/S0012-821X(02)00499-5.

Garzanti, E. (2008), Comment on "When and where did India and Asia collide?" by Jonathan C. Aitchison, Jason R. Ali, and Aileen M. Davis, J. Geophys. Res., 113, B04411, doi:10.1029/2007JB005276.

Gilder, S., Y. Chen, and S. Sen (2001), Oligo-Miocene magnetostratigraphy and rock magnetism of the Xishuigou section, Subei (Gansu Province, western China) and implications for shallow inclinations in central Asia, J. Geophys. Res., 106(B12), 30,50530,521, doi:10.1029/2001JB000325

Gilder, S., Y. Chen, J.-P. Cogné, X. Tan, V. Courtillot, D. Sun, and Y. Li (2003), Paleomagnetism of Upper Jurassic to Lower Cretaceous volcanic and sedimentary rocks from the western Tarim Basin and implications for inclination shallowing and absolute dating of the M-0 (ISEA?) chron, Earth Planet. Sci. Lett., 206, 587-600, doi:10.1016/S0012-821X (02)01074-9 
Gordon, R. G. (1998), The plate tectonic approximation: Plate nonrigidity, diffuse plate boundaries, and global plate reconstructions, Annu. Rev. Earth Planet. Sci., 26(1), 615-642, doi:10.1146/annurev. earth.26.1.615

Hankard, F., J.-P. Cogné, and V. Kravchinsky (2005), A new Late Cretaceous paleomagnetic pole for the west of Amuria block (Khurmen Uul, Mongolia), Earth Planet. Sci. Lett., 236, 359-373, doi:10.1016/j.epsl.2005.05.033.

Hankard, F., J.-P. Cogné, V. A. Kravchinsky, L. Carporzen, A. Bayasgalan, and P. Lkhagvadorj (2007a), New Tertiary paleomagnetic poles from Mongolia and Siberia at 40,30, 20, and 13 Ma: Clues on the inclination shallowing problem in central Asia, J. Geophys. Res., 112, B02101, doi:10.1029/ 2006JB004488.

Hankard, F., J.-P. Cogné, X. Quidelleur, A. Bayasgalan, and P. Lkhagvadorj (2007b), Paleomagnetism and $\mathrm{K}$-Ar dating of Cretaceous basalts from Mongolia, Geophys. J. Int., 169, 898-908, doi:10.1111/ j.1365-246X.2007.03292.X

Hankard, F., J.-P. Cogné, F. Lagroix, X. Quidelleur, V. A. Kravchinksy, A. Bayasgalan, and P. Lkhagvadorj (2008), Palaeomagnetic results from Palaeocene basalts from Mongolia reveal no inclination shallowing at $60 \mathrm{Ma}$ in central Asia, Geophys. J. Int., 172, 87-102, doi:10.1111/j.1365-246X.2007.03619.x.

Höck, V., G. Daxner-Höck, H. P. Schmid, D. Badamgarav, W. Frank, G. Furtmüller, O. Montag, R. Barsbold, Y. Khand, and J. Sodov (1997), Oligocene-Miocene sediments, fossils and basalts from the Valley of Lakes (central Mongolia) An integrated study, Mitt. Oesterr. Geol. Ge., 90, $83-125$.

Huang, B., J. D. A. Piper, Y. Wang, H. He, and R. Zhu (2005), Paleomagnetic and geochronological constraints on the post-collisional northward convergence of the southwest Tian Shan, NW China, Tectonophysics, 409, 107-124, doi:10.1016/j. tecto.2005.08.018

Johnson, C. L., et al. (2008), Recent investigations of the $0-5$ Ma geomagnetic field recorded by lava flows, Geochem. Geophys. Geosyst., 9, Q04032, doi:10.1029/2007GC001696.

Jolivet, M., et al. (2007), Mongolian summits An uplifted, flat, but still preserved erosion surface, Geology, 35(10), 871-874, doi:10.1130/ G23758A.1.

Kapp, P., A. Yin, T. M. Harrison, and L. Ding (2005) Cretaceous-Tertiary shortening, basin development, and volcanism in central Tibet, Geol. Soc. Am. Bull., 117, 865-878, doi:10.1130/B25595.1.

Kapp, P., P. G. DeCelles, A. L. Leier, J. M. Fabijanic, S. He, A. Pullen, G. E. Gehrels, and L. Ding (2007), The Gangdese retroarc thrust belt revealed, GSA Today, 17, 4-9, doi:10.1130/GSAT01707A.1.

Kirschvink, J. L. (1980), The least squares line and plane and the analysis of paleomagnetic data, Geophys. J. R. Astron. Soc., 62, 699-718.

Long, S. P., N. McQuarrie, T. Tobgay, and D. Grujic (2010), Geometry and crustal shortening of the Himalayan fold-thrust belt, eastern and central Bhutan, Geol. Soc. Am. Bull., in press.

McFadden, P. L., and F. J. Lowes (1981), The discrimination of mean directions drawn from Fisher distributions, Geophys. J. R. Astron Soc., 67, 19-33.

McFadden, P. L., and M. W. McElhinny (1988), The combined analysis of remagnetization circles and direct observations in palaeomagnetism, Earth Planet. Sci. Lett., 87, 161-172, doi:10.1016/0012821X(88)90072-6.

Merril, R. T., M. W. McElhinny, and P. L. McFadden (1998), The Magnetic Field of the Earth, Int. Geophys. Ser., vol. 63, Academic, London.

Métivier, F., Y. Gaudemer, P. Tapponnier, and M. Klein (1999), Mass accumulation rates in Asia during the Cenozoic, Geophys. J. Int., 137, 280-318, doi:10.1046/j.1365-246X.1999.00802.x

Meyer, B, P. Tapponnier, L. Bourjot, F. Metivier, Y. Gaudemer, G. Peltzer, G. Shummin, and C. Zhitai (1998), Crustal thickening in the Gansu-Qinghai, lithospheric mantle, oblique and strike-slip controlled growth of the Tibetan Plateau, Geophys. J. Int., 135, 1-47, doi:10.1046/j.1365-246X.1998. 00567.x.

Molnar, P., and J. M. Stock (2009), Slowing of India's convergence with Eurasia since $20 \mathrm{Ma}$ and its implications for Tibetan mantle dynamics, Tectonics, 28, TC3001, doi:10.1029/2008TC002271.

Moreau, M.-G., J. Besse, F. Fluteau, and M. GreffLefftz (2007), A new global Paleocene-Eocene apparent polar wandering path loop by "stacking" magnetostratigraphies: Correlations with high latitude climatic data, Earth Planet. Sci. Lett., 260, 152-165, doi:10.1016/j.eps1.2007.05.025.

Patzelt, A., H. Li, J. Wang, and E. Appel (1996), Palaeomagnetism of Cretaceous to Tertiary sediments from southern Tibet: Evidence for the extent of the northern margin of India prior to the collision with Eurasia, Tectonophysics, 259, 259-284.

Riisager, P., J. Riisager, N. Abrahamsen, and R. Waagstein (2002), New paleomagnetic pole and magnetostratigraphy of Faroe Islands flood volcanics, North Atlantic igneous province, Earth Planet. Sci. Lett., 201, 261-276, doi:10.1016/S0012-821X(02)00720-3.

Ritts, B. D., Y. Yue, S. A. Graham, E. R. Sobel, O. A. Abbink, and D. Stockli (2008), From sea level to high elevation in 15 million years: Uplift history of the northern Tibetan Plateau margin in the Altun Shan, Am. J. Sci., 308(5), 657-678, doi:10.2475/ 05.2008.01.

Ruddiman, W. F., J. E. Kutzbach, and I. C. Prentice (1997), Testing climatic effects of orography and $\mathrm{CO}_{2}$ with general circulation and biome models, in Tectonic Uplift and Climate Change, edited by W. F. Ruddiman, pp. 203-235, Plenum, New York.

Schettino, A., and C. R. Scotese (2005), Apparent polar wander paths for the major continents (200 Ma to the present day): A palaeomagnetic reference frame for global tectonic reconstructions, Geophys. J. Int., 163, 727-759, doi:10.1111/j.1365-246X.2005. 02638.x

Si, J., and R. Van der Voo (2001), Too-low magnetic inclinations in central Asia: An indication of a long-term Tertiary non-dipole field?, Terra Nova, 13(6), 471-478, doi:10.1046/j.1365-3121.2001. 00383.x.

Tan, X., K. P. Kodama, H. Chen, D. Fang, D. Sun, and Y. Li (2003), Paleomagnetism and magnetic anisotropy of Cretaceous red beds from the Tarim basin, northwest China: Evidence for a rock magnetic cause of anomalously shallow paleomagnetic inclinations from central Asia, J. Geophys. Res., 108(B2), 2107, doi:10.1029/2001JB001608.

Tan, X., S. Gilder, K. P. Kodama, W. Jiang, Y. Han, H. Zhang, H. Xu, and D. Zhou (2010), New paleomagnetic results from the Lhasa block: Revised estimation of latitudinal shortening across Tibet and implications for dating the India-Asia collision, Earth Planet. Sci. Lett., 293, 396-404.

Tapponnier, P., Z. Xu, F. Roger, B. Meyer, N. Arnaud, G. Wittlinger, and J. Yang (2001), Oblique stepwise rise and growth of the Tibetan Plateau, Science, 294, 1671-1677, doi:10.1126/science. 105978

Tauxe, L. (2005), Inclination flattening and the geocentric axial dipole hypothesis, Earth Planet. Sci. Lett., 233, 247-261, doi:10.1016/j.eps1.2005.01.027.

Tauxe, L., and D. V. Kent (2004), A simplified statistical model for the geomagnetic field and the detection of shallow bias in paleomagnetic inclinations: Was the ancient magnetic field dipolar?, in Timescales of the Paleomagnetic Field, Geophys. Monogr. Ser., vol. 145, edited by J. E. T. Channell et al., pp. 101-115, AGU, Washington, D. C.
Torsvik, T. H., and R. Van der Voo (2002), Refining Gondwana and Pangea Palaeogeography: Estimates of Phanerozoic non-dipole (octupole) fields, Geophys. J. Int., 151, 771-794, doi:10.1046/ j.1365-246X.2002.01799.x.

Torsvik, T. H., J. Mosar, and E. A. Eide (2001), Cretaceous-Tertiary geodynamics: A North Atlantic exercise, Geophys. J. Int., 146, 850-866, doi:10.1046/j.0956-540x.2001.01511.x.

Torsvik, T. H., R. Van der Voo, and T. F. Redfield (2002), Frontier-Relative hotspot motions versus true polar wander, Earth Planet. Sci. Lett., 202, 185-200, doi:10.1016/S0012-821X(02)00807-5.

Torsvik, T. H., R. D. Müller, R. Van der Voo, B. Steinberger, and C. Gaina (2008), Global plate motion frames: Toward a unified model, Rev. Geophys., 46, RG3004, doi:10.1029/2007RG000227.

Vandamme, D. (1994), A new method to determine paleosecular variation, Phys. Earth Planet. Inter. 85, 131-142, doi:10.1016/0031-9201(94)90012-4.

Van der Voo, R. (1990), The reliability of paleomagnetic data, Tectonophysics, 184, 1-9, doi:10.1016/ 0040-1951(90)90116-P.

Van der Voo, R., and T. H. Torsvik (2001), Evidence for late Paleozoic and Mesozoic non-dipole fields provides an explanation for the Pangea reconstruction problems, Earth Planet. Sci. Lett., 187, 71-81, doi:10.1016/S0012-821X(01)00285-0.

Van der Voo, R., W. Spakman, and H. Bijwaard (1999), Mesozoic subducted slabs under Siberia, Nature, 397, 246-249, doi:10.1038/16686.

van Hinsbergen, D. J. J., G. B. Straathof, K. F. Kuiper, W. D. Cunningham, and J. R. Wijbrans (2008), No rotations during transpressional orogeny in the Gobi Altai: Coinciding Mongolian and Eurasian apparen polar wander paths, Geophys. J. Int., 173, 105-126, doi:10.1111/j.1365-246X.2007.03712.x.

Vassallo, R., M. Jolivet, J.-F. Ritz, R. Braucher, C. Larroque, C. Sue, M. Todbileg, and D. Javkhlanbold (2007), Uplift age and rates of the Gurvan Bogd system (Gobi-Altay) by apatite fission track analysis, Earth Planet. Sci. Lett., 259, 333-346, doi:10.1016/j. eps1.2007.04.047.

Wang, X., B. Wang, Z. Qiu, G. Xie, J. Xie, W. Downs, Z. Qiu, and T. Deng (2003), Danghe area (western Gansu, China) biostratigraphy and implications for depositional history and tectonics of northern Tibetan Plateau, Earth Planet. Sci. Lett., 208, 253-269, doi:10.1016/S0012-821X(03)00047-5.

Whitford-Stark, J. L. (1987), A Survey of Cenozoic Volcanism on Mainland Asia, 74 pp., Geol. Soc. of Am., Boulder, Colo.

Yan, M., R. Van der Voo, X. Fang, J. M. Parés, and D. K. Rea (2006), Paleomagnetic evidence for a mid-Miocene clockwise rotation of about $25^{\circ}$ of the Guide Basin area in NE Tibet, Earth Planet Sci. Lett., 241, 234-247, doi:10.1016/j.epsl.2005. 10.013 .

Yin, A., et al. (2002), Tectonic history of the Altyn Tagh fault system in northern Tibet inferred from Cenozoic sedimentation, Geol. Soc. Am. Bull., 114, 1257-1295, doi:10.1130/0016-7606(2002) 114<1257:THOTAT $>2.0$. CO;

Zijderveld, J. D. A. (1967), A. C. demagnetization of rocks: Analysis of results, in Methods in Palaeomagnetism, edited by D. W. Collinson, K. M. Creer, and S. K. Runcorn, pp. 254-286, Elsevier, Amsterdam.

G. Dupont-Nivet, Paleomagnetic Laboratory "Fort Hoofddijk," Faculty of Geosciences, Utrecht University, Budapestlaan 17, NL-3584 CD Utrecht, Netherlands. (gdn@geo.uu.nl)

T. H. Torsvik and D. J. J. van Hinsbergen, Physics of Geological Processes, University of Oslo, Sem Sælands vei 24, N-0316 Oslo, Norway. (trond.torsvik@ngu.no) 